\title{
Boosting Activity and Stability of Metal Single-Atom Catalysts via Regulation of Coordination Number and Local Composition
}

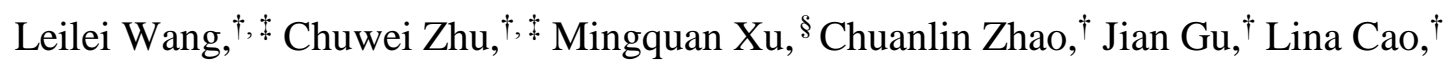
Xiaohui Zhang, ${ }^{\dagger}$ Zhihu Sun, ${ }^{\mathbb{I}}$ Shiqiang Wei, ${ }^{\mathbb{I}}$ Wu Zhou, ${ }^{\S}$ Wei-Xue Li, ${ }^{\dagger}, *$ Junling Lu ${ }^{\dagger, *}$ ${ }^{\dagger}$ Hefei National Laboratory for Physical Sciences at the Microscale, Department of Chemical Physics, School of Chemistry and Materials Science, University of Science and Technology of China, Hefei, Anhui 230026, China ${ }^{\mathbb{I}}$ National Synchrotron Radiation Laboratory, University of Science and Technology of China, Hefei, Anhui 230029 China

${ }^{\S}$ School of Physical Sciences, CAS Key Laboratory of Vacuum Physics, CAS Center for Excellence in

Topological Quantum Computation, University of Chinese Academy of Sciences, Beijing 100049 China. 


\section{Experimental section}

\section{Catalyst synthesis}

Preparation of NCs. To prepare the NC support, g- $\mathrm{C}_{3} \mathrm{~N}_{4}$ was first synthesized. Here 30 gram of Urea (Sinopharm Chemical Reagent Co., Ltd AR grade) was loaded into a ceramic crucible $(100 \mathrm{~mL})$ with a cover, then it was heated up in a muffle furnace from room temperature (RT) to $550{ }^{\circ} \mathrm{C}$ at a heating rate of $5{ }^{\circ} \mathrm{C} / \mathrm{min}$ and kept at this temperature for $4 \mathrm{~h}$. After cooling the crucible to room temperature, $g-\mathrm{C}_{3} \mathrm{~N}_{4}$ was obtained.

Next, we synthesized the $\mathrm{g}-\mathrm{C}_{3} \mathrm{~N}_{4} @$ Glu precursor. Here $\mathrm{g}-\mathrm{C}_{3} \mathrm{~N}_{4}(0.75 \mathrm{~g})$ was dispersed in an aqueous glucose solution $(0.3 \mathrm{M}, 60 \mathrm{~mL})$, and then sonicated for $6 \mathrm{~h}$ at RT. The resulting suspension was transferred to a $100 \mathrm{~mL}$ autoclave with internal Teflon lining. The autoclave was put in an oven, and heated up to $180{ }^{\circ} \mathrm{C}$ and remained for 10 $\mathrm{h}$ at this temperature. The product $\left(\mathrm{g}-\mathrm{C}_{3} \mathrm{~N}_{4} @ \mathrm{Glu}\right)$ was obtained after the sequential steps of centrifugation, thorough washing with deionized water and ethanol each for three times, and drying in the oven at $80{ }^{\circ} \mathrm{C}$ overnight.

After that, the g- $\mathrm{C}_{3} \mathrm{~N}_{4} @$ Glu precursor was calcined at $600,800,900$, and $1000{ }^{\circ} \mathrm{C}$ for $1 \mathrm{~h}$ and $1000^{\circ} \mathrm{C}$ for $3 \mathrm{~h}$ under $\mathrm{Ar}$ atmosphere to the NC supports. These NCs are denoted as NC-600, NC-800, NC-900, NC-1000-1h, and NC-1000-3h, respectively.

Preparation of $\mathrm{Pt}_{1} / \mathrm{NC}$ single-atom catalysts (SACs). Pt ALD was carried out on a viscous flow stainless steel tube reactor system (ACME (Beijing) Technology Co., Ltd) by exposing the NC supports NCs to trimethyl (methylcyclopentadienyl)-platinum (IV) ( $\mathrm{MeCpPtMe}_{3}$, Sigma-Aldrich, 98\%) and oxygen at $150{ }^{\circ} \mathrm{C} .{ }^{1}$ Ultrahigh purity $\mathrm{N}_{2}$ 
(99.999\%, Nanjing Special Gases) was used as the carrier gas at a flow rate of 200 $\mathrm{mL} / \mathrm{min}$. The Pt precursor was heated up to $65^{\circ} \mathrm{C}$ to get a sufficient vapor pressure. Then the NC support was loaded into the ALD reactor. After stabilizing at $150^{\circ} \mathrm{C}$ for 30 min, one cycle of $\mathrm{Pt} A L D$ was conducted to prepare the $\mathrm{Pt}_{1} / \mathrm{NC}$ catalysts. The timing sequence was $15,250,50$, and $300 \mathrm{sec}$ for the $\mathrm{MeCpPtMe}_{3}$ exposure, $\mathrm{N}_{2}$ purge, $\mathrm{O}_{2}$ exposure, and $\mathrm{N}_{2}$ purge, respectively. The resulting materials were denoted as $\mathrm{Pt}_{1} / \mathrm{NC}$ 600, $\mathrm{Pt}_{1} / \mathrm{NC}-800, \mathrm{Pt}_{1} / \mathrm{NC}-900, \mathrm{Pt}_{1} / \mathrm{NC}-1000-1 \mathrm{~h}, \mathrm{Pt}_{1} / \mathrm{NC}-1000-3 \mathrm{~h}$, and $\mathrm{Pt}_{1} / \mathrm{C}-1000-3 \mathrm{~h}$, respectively.

\section{Catalyst characterization}

The $\mathrm{Pt}$ loadings in these $\mathrm{Pt}_{1} / \mathrm{NC}$ catalysts were determined by an inductively coupled plasma atomic emission spectrometer (ICP-AES); Therein all samples were dissolved in hot aqua regia. The BET surface areas of the NC supports was measured on a Micromeritics ASAP 2020 system. Raman spectra were recorded on a LabRAM HR Raman spectrometer with a $514 \mathrm{~nm}$ Ar laser in backscattering geometry.

The morphology of $\mathrm{Pt}_{1} / \mathrm{NC}$ catalysts was characterized on an aberration-corrected HAADF-STEM instrument at $200 \mathrm{kV}$ (JEOL-2010F, University of Science and Technology of China) and transmission electron microscopy (TEM, JEOL-2010, University of Science and Technology of China) at $200 \mathrm{kV}$. The energy-dispersive spectrometer (EDS) mappings were performed on the JEOL JEM-2010F microscope at $200 \mathrm{kV}$.

XPS measurements were taken on a Thermo-VG Scientific Escalab 250 
spectrometer equipped with an $\mathrm{Al}$ anode $(\mathrm{Al} \mathrm{K} \alpha=1486.6 \mathrm{eV})$. Ex situ XAFS measurements at $\mathrm{Pt} L_{3}$-edge $(11564 \mathrm{eV})$ were performed with the $\mathrm{Si}$ (111) monochromator at the 1W1B beamline of Beijing Synchrotron Radiation Facility (BSRF), China. The storage ring of BSRF worked at $2.5 \mathrm{GeV}$ with a maximum current of $250 \mathrm{~mA}$.

\section{Catalytic testing}

The reaction of $p$-CNB hydrogenation was carried out in a $100 \mathrm{~mL}$ stainless autoclave at 3 bar. Prior to the reaction test, the $\mathrm{Pt}_{1} / \mathrm{NC}$ catalysts were first reduced in $10 \% \mathrm{H}_{2}$ /Ar flow at $300{ }^{\circ} \mathrm{C}$ for $1 \mathrm{~h}$ and then immediately transferred into the autoclave. The amount of these catalysts were normalized to the same Pt content of $0.0004 \mathrm{mmol}$. $2 \mathrm{mmol} p$-CNB substrate and $0.67 \mathrm{mmol} \mathrm{m}$-xylene as external standard dissolved in 40 $\mathrm{mL}$ ethanol were then added into the autoclave. Next, the autoclave was vigorously stirred at a rate of $1500 \mathrm{rpm}$ and flushed with 3 bar Helium for several times to drain the air out. Thereafter, the autoclave was heated up to $65^{\circ} \mathrm{C}$ at a heating rate of $3{ }^{\circ} \mathrm{C} / \mathrm{min}$. After that hydrogen was introduced to the autoclave at a pressure of 3 bar to start the reaction. The reaction products were analyzed using a Shimadzu GC-2014 gas chromatograph equipped with a Rtx-1 capillary column, an auto-injector, and a flame ionization detector (FID). For the stability test, the solution was filtered after each run and the used catalyst was washed with ethanol and then dried overnight for the next run.

The turnover frequencies (TOFs) of these $\mathrm{Pt}_{1} / \mathrm{NC}$ catalysts were calculated according to the equation: 


$$
\mathrm{TOF}=\frac{n_{p-\mathrm{CNB}}}{n_{\text {metal }}} \cdot \frac{1}{t}
$$

Here $n_{p-\mathrm{CNB}}$ is the mole of $p$-CNB consumed, while $n_{\text {metal }}$ is the total mole of Pt in the sample, and $t$ is the reaction time in hour.

For the $\mathrm{H}-\mathrm{D}$ exchange experiments, the $\mathrm{Pt}_{1} / \mathrm{NC}$ catalyst diluted with 1 gram of fine quartz chips was loaded in fixed-bed quartz tube reactor, where the amounts of $\mathrm{Pt}_{1} / \mathrm{NC}$ catalysts were normalized to the same Pt content. The catalyst was first reduced in $10 \% \mathrm{H}_{2}$ in $\mathrm{Ar}$ at $300{ }^{\circ} \mathrm{C}$ for 1 hour prior to reaction. Next, a gas feed consisting of $10 \%$ deuterium $\left(\mathrm{D}_{2}\right)$ and $10 \% \mathrm{H}_{2}$ with Ar balance gas was introduced to the reactor at a total flow rate of $25 \mathrm{~mL} / \mathrm{min}$. The sample temperature was $65^{\circ} \mathrm{C}$. The signals of $\mathrm{H}_{2}$ $(\mathrm{m} / \mathrm{z}=2), \mathrm{HD}(\mathrm{m} / \mathrm{z}=3)$, and $\mathrm{D}_{2}(\mathrm{~m} / \mathrm{z}=4)$ were recorded by an online mass spectrometry.

\section{DFT calculations}

Periodic density functional theory (DFT) calculations were performed using the Vienna $\mathrm{Ab}$ initio Simulation Package $(\mathrm{VASP})^{2}$, at the level of generalized gradient approximation (GGA) using Perdew-Burke-Ernzerhof (PBE) exchange-correlation functional $^{3}$. The optB86b van der Waals (vdW) functional was used to account for vdW contribution $^{4}$. The projector-augmented wave (PAW) method $^{5}$, was used to describe the core electrons. The Kohn-Sham valence states were expanded in a plane wave basis set with a kinetic energy cutoff of $400 \mathrm{eV}$.

The model structures used in our simulations were based on free-standing graphene with a $5 \times 5$ supercell, containing a total of 50 carbon atoms. A vacuum space of $\sim 20 \AA$ in the $z$ direction was set to avoid interactions between periodic images. 
Brillouin zone was sampled with a $\Gamma$-centered $3 \times 3 \times 1$ Monkhorst-Pack k-point grid. ${ }^{6}$ To model the less defective surfaces, a carbon vacancy dimer (a pair of adjacent $\mathrm{C}$ vacancies) was created to host $\mathrm{Pt}_{1}$, which is coordinated with a total number of 4 adjacent $\mathrm{C}$ or $\mathrm{N}$ atoms ( $\mathrm{C} / \mathrm{N}$ ratio spans from 0 to 4$)$. To model the more defective surfaces, one more adjacent $\mathrm{C}$ vacancy was created on the carbon vacancy dimer surface, $\mathrm{Pt}_{1}$ thus becomes coordinated with a total number of 3 adjacent $\mathrm{C}$ or $\mathrm{N}$ atoms. The $\mathrm{Pt}_{1}-\mathrm{N}_{\mathrm{x}} \mathrm{C}_{\mathrm{y}}$ terminology was used to describe that the single $\mathrm{Pt}$ atom is coordinated with adjacent $\mathrm{x} \mathrm{N}$ and $\mathrm{y} \mathrm{C}$ atoms. In particular, $\mathrm{H}_{2}$ dissociation in the unoccupied $\mathrm{C}$ vacancy turns out to be quite facile for the more defective models except for $\mathrm{Pt}_{1}-\mathrm{N}_{3}$, therefore the proposed structures for these models contain two pre-adsorbed $\mathrm{H}^{*}$ (similar to the general treatment on nanographene cluster models).

Geometry optimization and transition state search were converged to the level that the maximum residual force was $0.02 \mathrm{eV} / \mathrm{A}$ or less and $0.05 \mathrm{eV} / \AA ̊$ or less, respectively, in all relaxed degrees of freedom. Transition states were located using the climbingimage nudged elastic band method ${ }^{7}$ and the dimer $\operatorname{method}^{8}$, then verified to have only one vibrational mode with a negative curvature in the direction of bond forming or breaking process. Vibrational modes and frequencies were calculated using a finite difference approximation approach of the dynamical matrix with a displacement of 0.02 $\AA$. The formation energy was calculated as $\Delta E_{\mathrm{f}}=E_{\mathrm{Pt}-\mathrm{NC}}-E_{\mathrm{NC}}-E_{\mathrm{Pt}}$, where $E_{\mathrm{Pt}-\mathrm{NC}}, E_{\mathrm{NC}}$, $E_{\mathrm{Pt}}$ refer to the energy of $\mathrm{Pt}_{1}-\mathrm{NC}$ model surface, the energy of the clean defective nitrogen-doped graphene, and the energy of bulk Pt, respectively. Due to cohesive energies in bulk metal, the formation energies reported here are thus the upper bound. 
The equilibrium lattice constant of Pt was calculated to be $3.948 \AA$, in close agreement with the experiment value of $3.92 \AA{ }^{9}{ }^{9}$ The reaction energy for $\mathrm{H}_{2}$ dissociative on $\mathrm{Pt}_{1}$ NC model surface was calculated as $\Delta E_{\mathrm{r}}=E_{\mathrm{FS}}-E_{\mathrm{slab}}-E_{\mathrm{gas}}$, where $E_{\mathrm{FS}}, E_{\mathrm{slab}}$ and $E_{\mathrm{gas}}$ refer to the energy of the $\mathrm{Pt}_{1}-\mathrm{NC}$ slab with dissociative adsorbed $\mathrm{H}_{2}$, the energy of the clean slab, and the energy of the gas-phase $\mathrm{H}_{2}$ in a neutral state , respectively. The activation barrier for $\mathrm{H}_{2}$ dissociation was calculated as $E_{\mathrm{a}}=E_{\mathrm{TS}}-E_{\mathrm{slab}}-E_{\mathrm{gas}}$, where $E_{\mathrm{TS}}$ refers to the energy of the transition state for $\mathrm{H}_{2}$ dissociation. Zero-point energy corrections were not included here. 

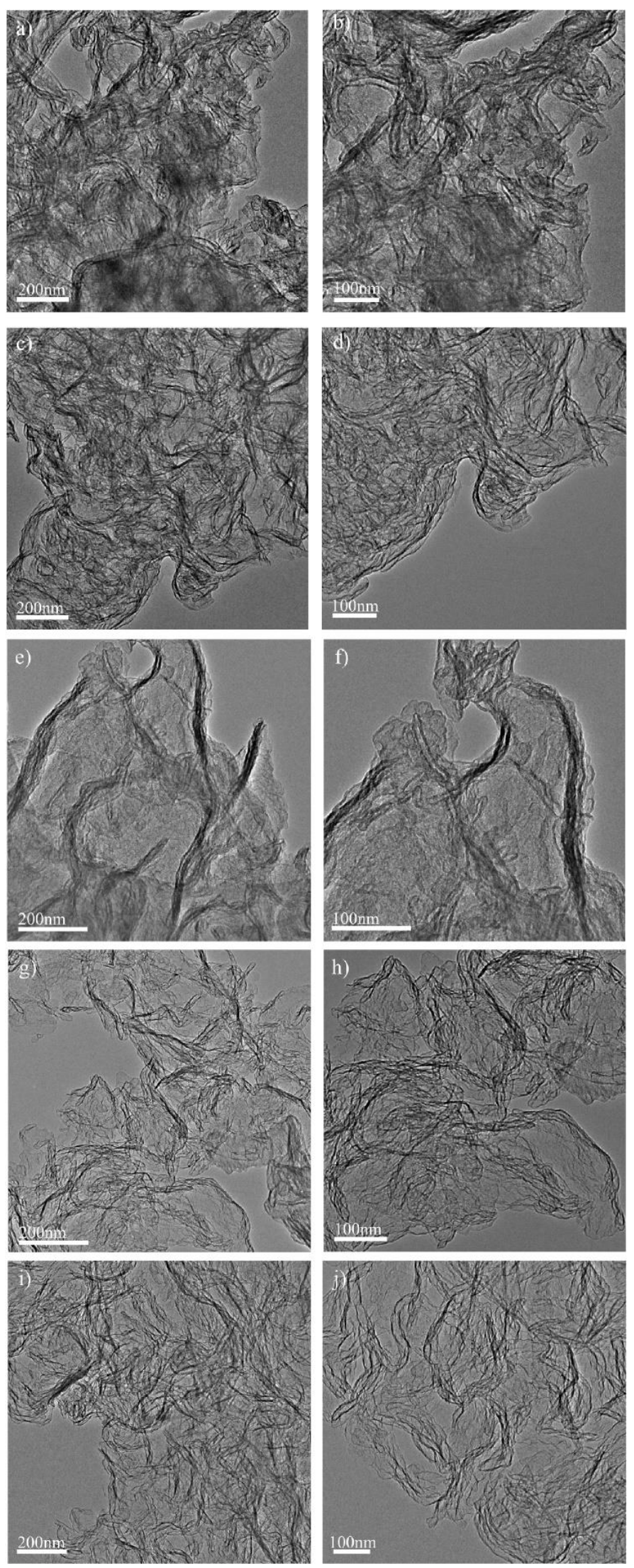

Figure S1. Representative TEM images of NC-600 (a,b), NC-800 (c,d), NC-900 (e,f), NC-1000-1h (g,h) and NC-1000-3h (i,j) at low magnifications. 


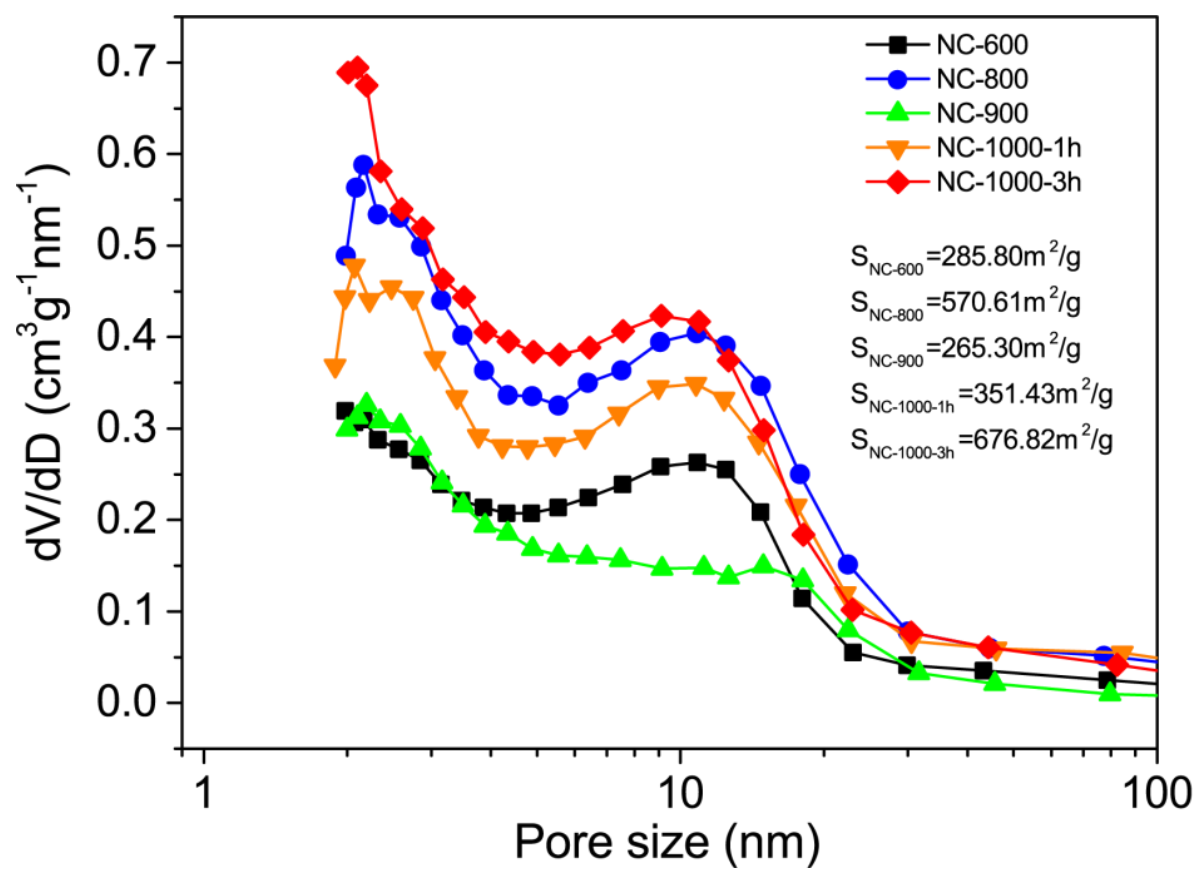

Figure S2. Specific surface areas and pore size distribution of NC supports. The pore sizes of NCs were in the range of 1-10 nm. The BET specific surface areas of these NC supports were also indicated.

\section{Supporting Notes:}

During high temperature-treatment, $\mathrm{N}$-doped carbon supports could release a significant amount of gas, which would crack the carbon support and introduce pores into the support, thus increasing the surface area. While along the high temperature-treatment, the formed pores might also collapse or be refilled, which causes the decrease of surface area. The amount or the rate of gas-releasing varies largely with the $\mathrm{N}$ content and the temperature. Consequently, the surface areas of carbon-based support could vary considerably depending on the balance of gasreleasing and pore-collapsing rates as varying temperatures. In fact, similar phenomenon has been reported in the previous literature..$^{10-12}$ 


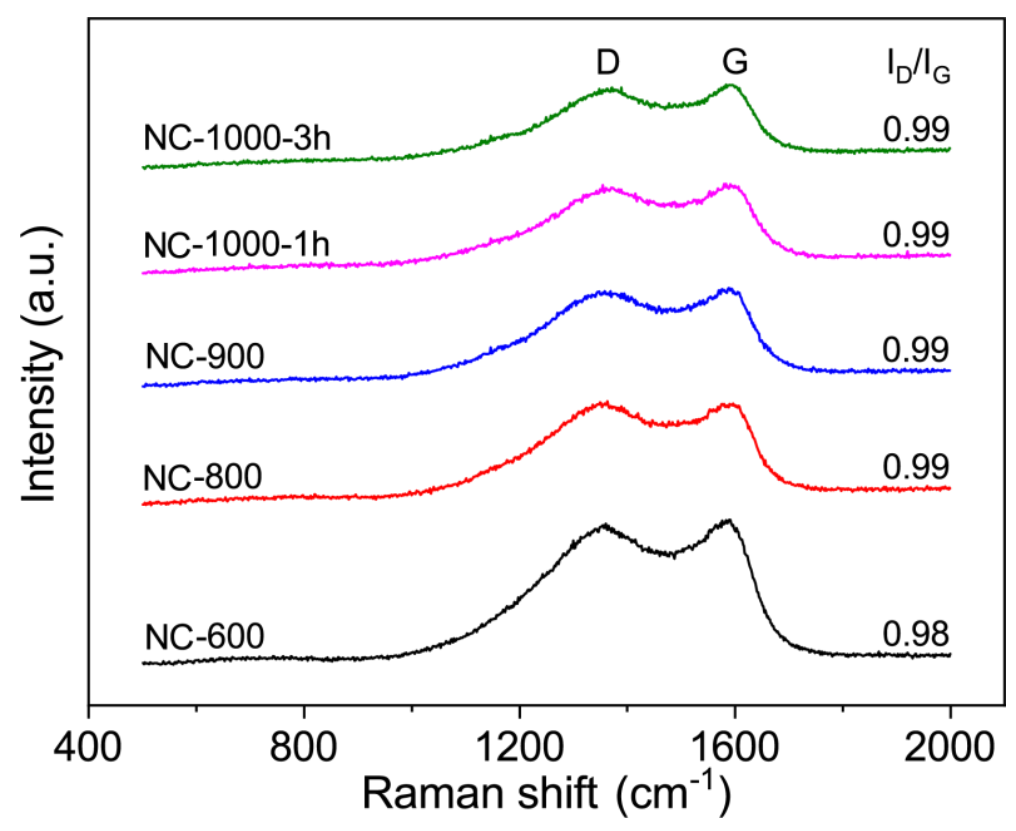

Figure S3. Raman spectra of NC supports. All samples showed two peaks at 1350 and $1590 \mathrm{~cm}^{-1}$, corresponding to the $\mathrm{D}$ and $\mathrm{G}$ band of carbon. 

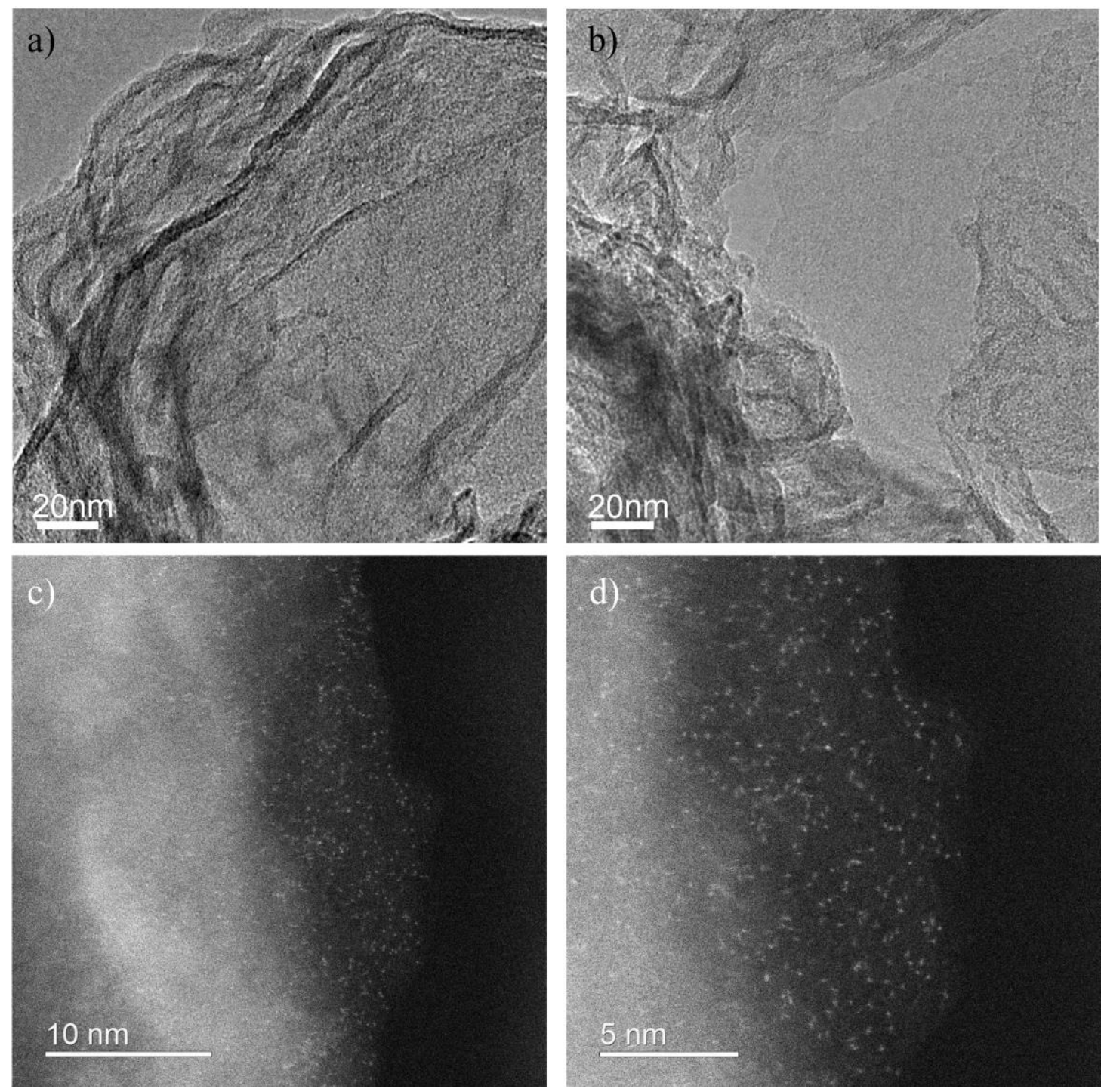

Figure S4. Representative TEM images $(a, b)$ and HAADF-STEM images (c, d) of $\mathrm{Pt}_{1} / \mathrm{NC}-600$ at high-magnifications. No any Pt clusters/particles were observed. 

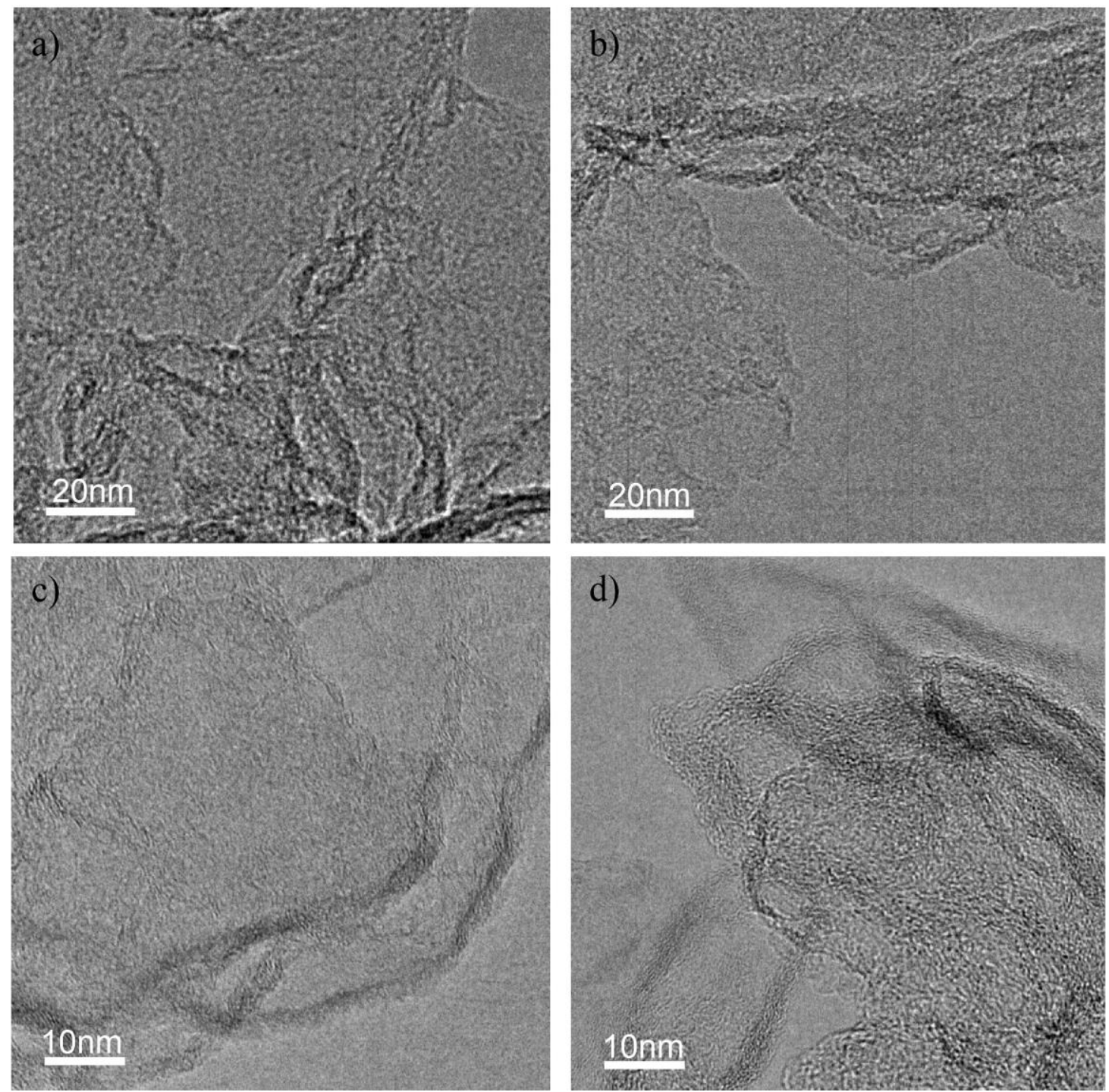

Figure S5. Representative TEM images of $\mathrm{Pt}_{1} / \mathrm{NC}-800$ at (a, b) low- and (c, d) highmagnifications. No any Pt clusters/particles were observed. 

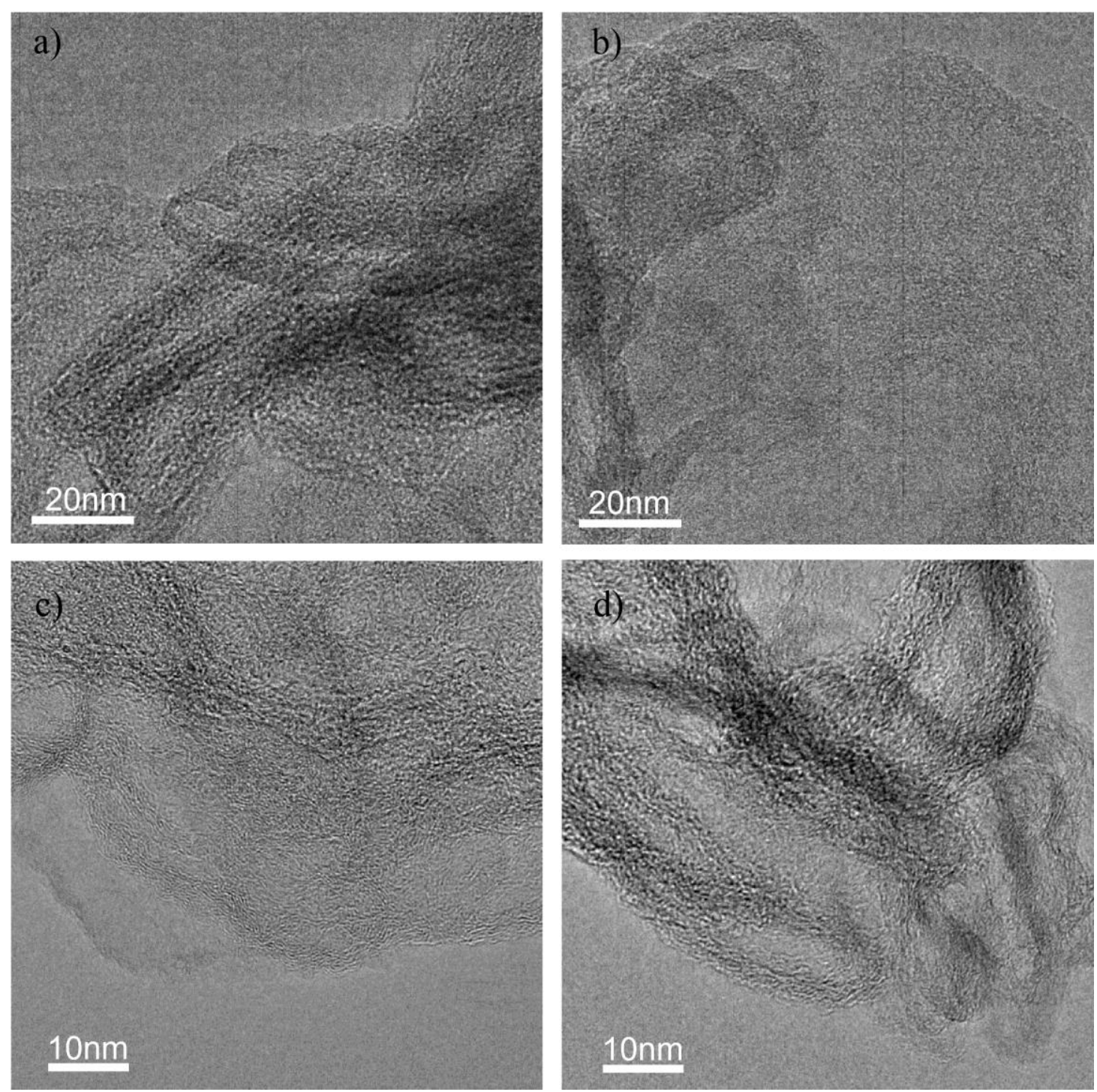

Figure S6. Representative TEM images of $\mathrm{Pt}_{1} / \mathrm{NC}-900$ at (a, b) low- and (c, d) highmagnifications. No any Pt clusters/particles were observed. 

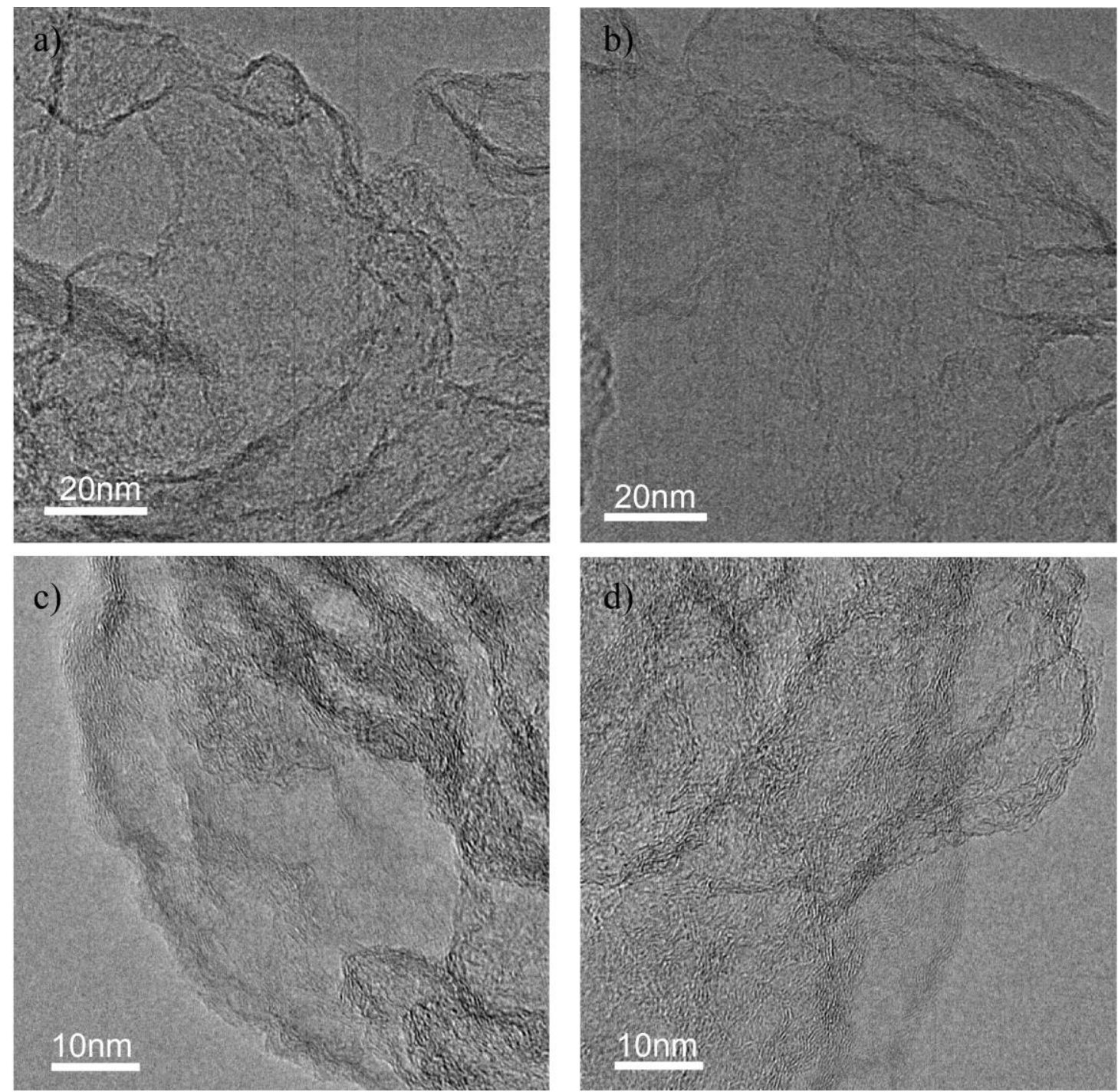

Figure S7. Representative TEM images of $\mathrm{Pt}_{1} / \mathrm{NC}-1000-1 \mathrm{~h}$ at $(\mathrm{a}, \mathrm{b})$ low- and $(\mathrm{c}, \mathrm{d})$ high-magnifications. 

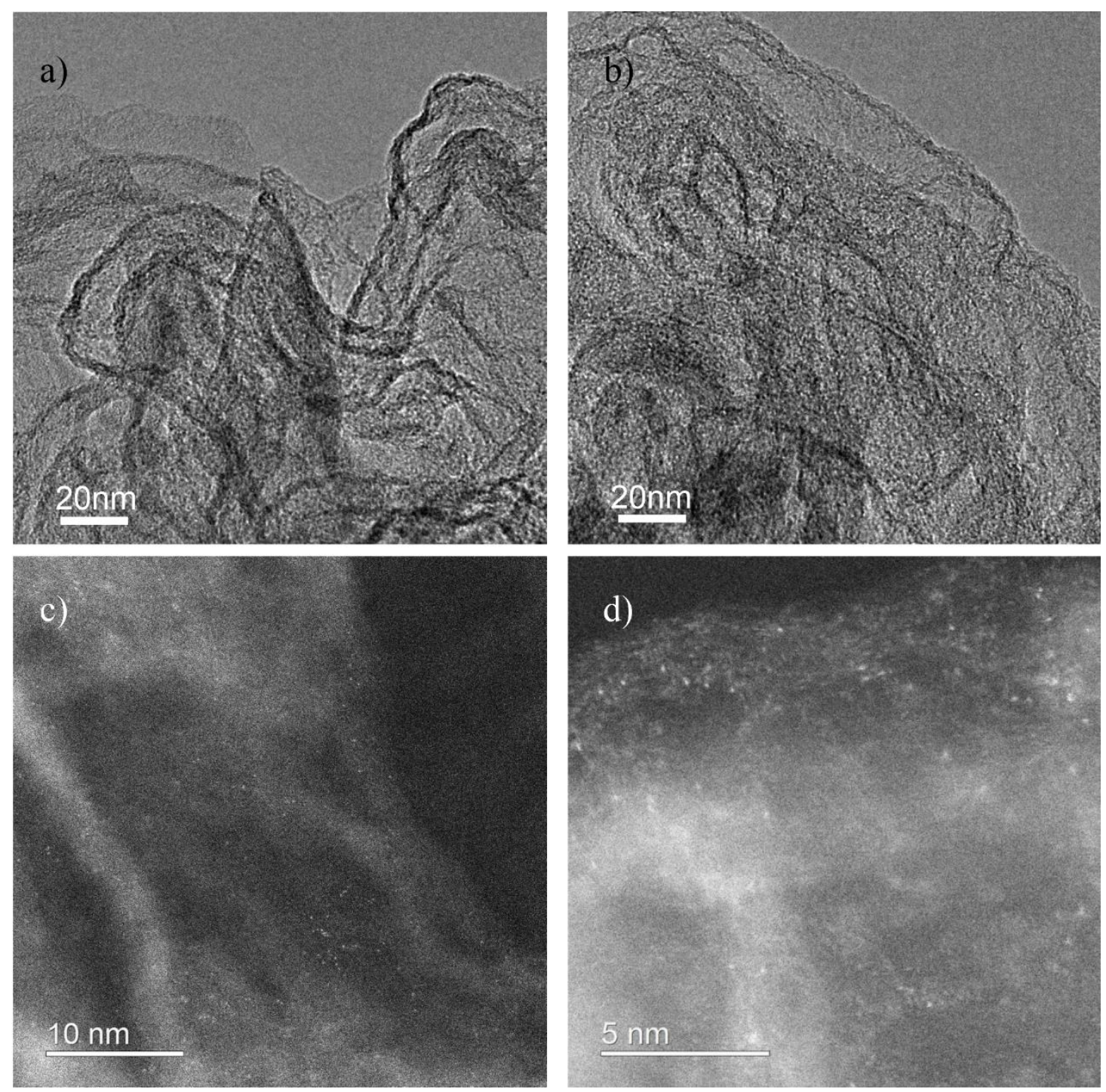

Figure S8. Representative TEM images ( $a, b)$ and HAADF-STEM images $(c, d)$ of $\mathrm{Pt}_{1} / \mathrm{NC}-1000-3 \mathrm{~h}$ at high-magnifications. No any Pt clusters/particles were observed. 

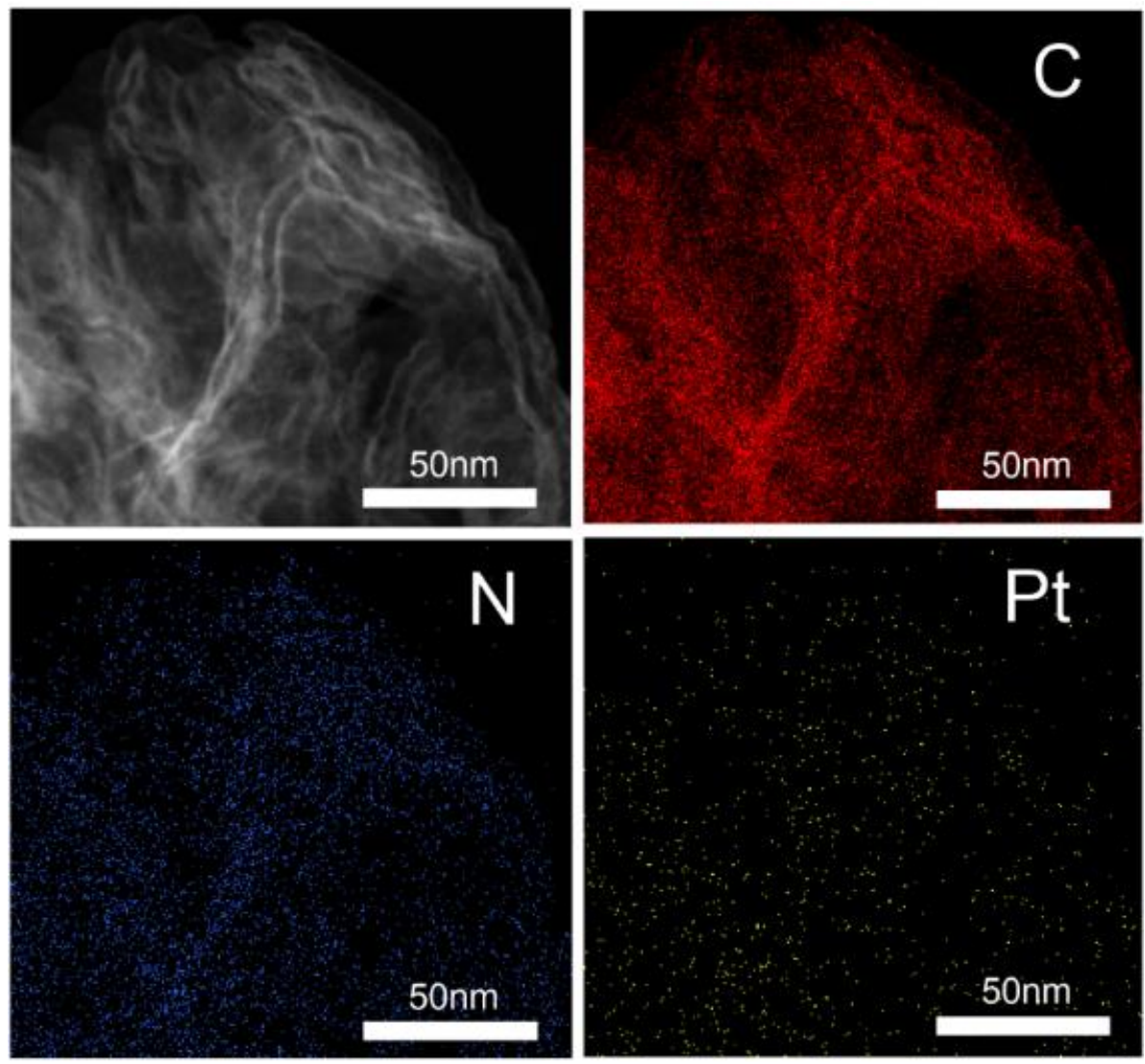

Figure S9. HAADF-STEM and corresponding elemental mapping of the C, N, and Pt elements in $\mathrm{Pt}_{1} / \mathrm{NC}-1000-3 \mathrm{~h}$. 
a)

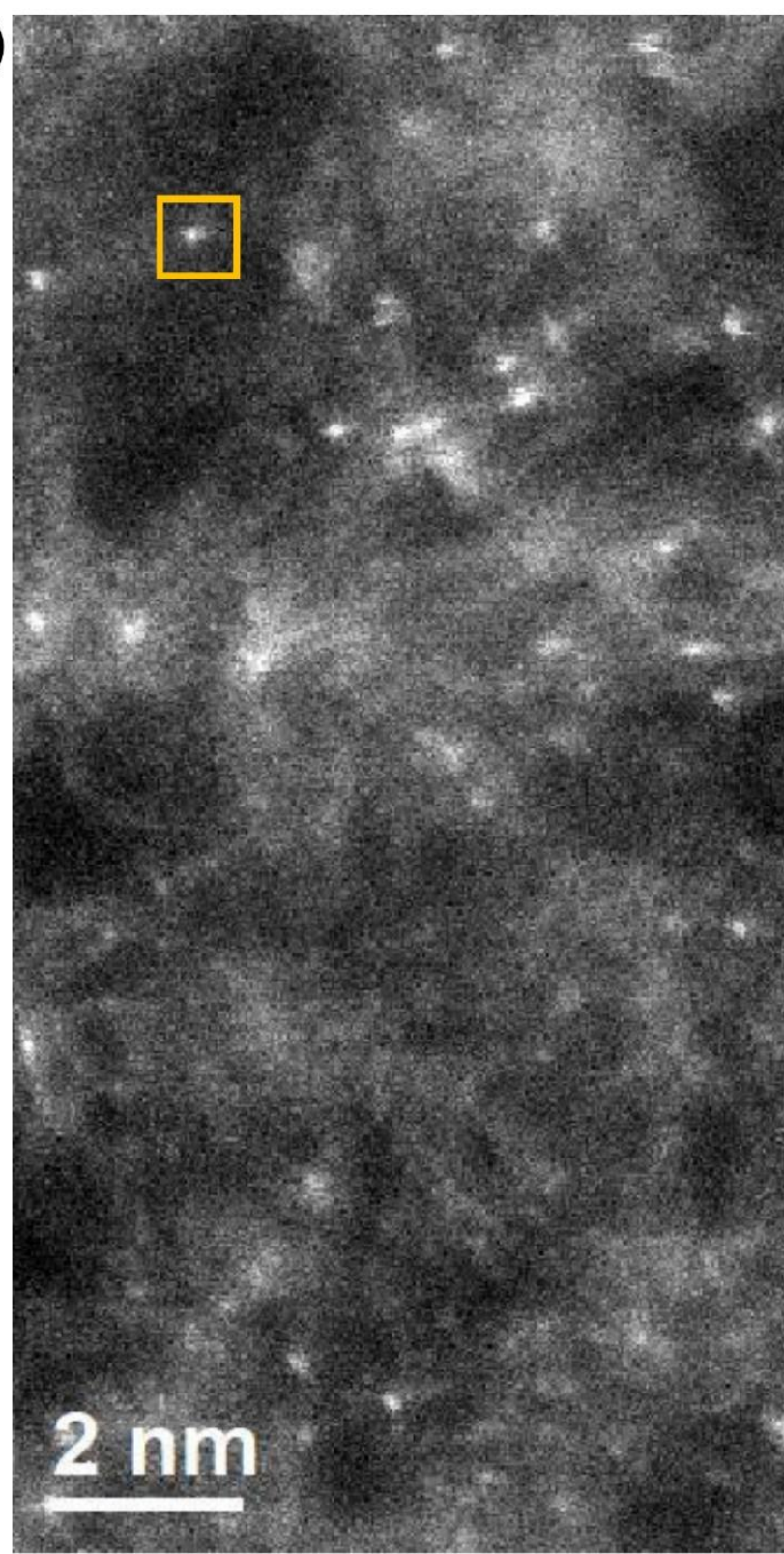

b)

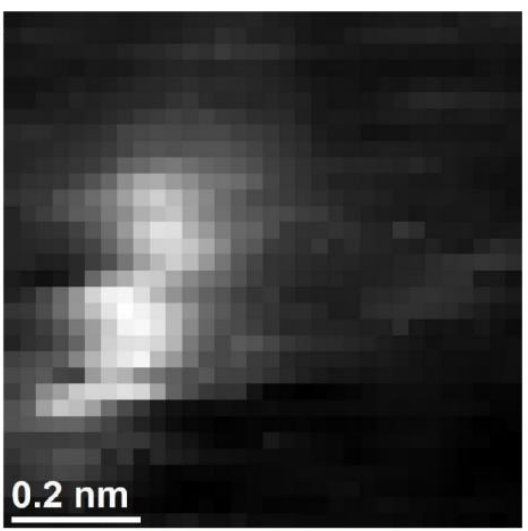

c)

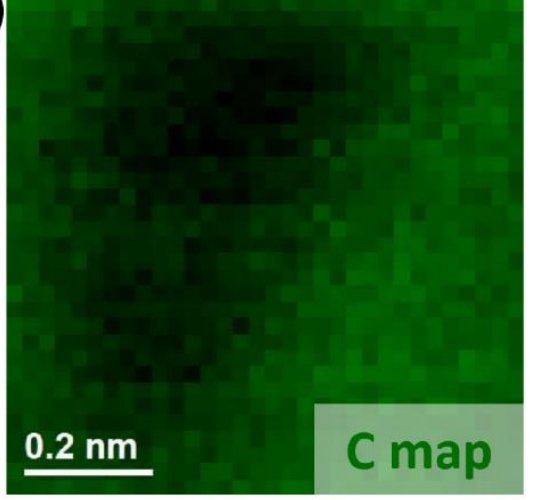

d)

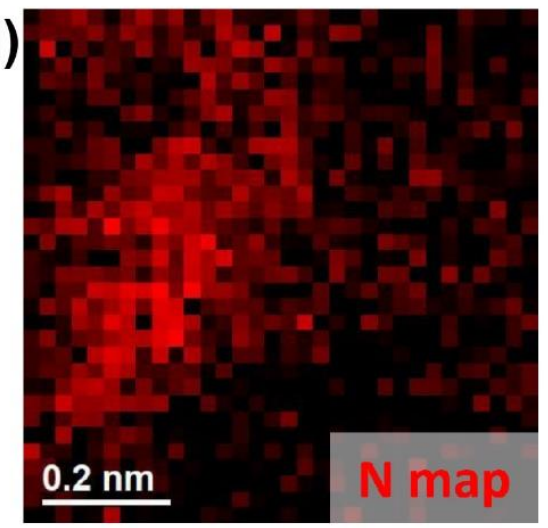

Figure S10. STEM-EELS characterization of $\mathrm{Pt}_{1} / \mathrm{NC}-1000-3 \mathrm{~h}$ sample. (a) Atomicresolution HAADF- STEM image. (b) The STEM image recorded in the orange rectangle area in (a) simultaneously during EELS mapping. The dislocation of the $\mathrm{Pt}$ atom was caused by the sample drift during EELS mapping recording. The EELS elemental mapping of $\mathrm{C}(\mathrm{d})$ and $\mathrm{N}(\mathrm{e})$ signals. Clearly, the spatial accordance of the $\mathrm{N}$ signal and Pt atom, unambiguously confirmed that the Pt atoms were deposited at the $\mathrm{N}$-related anchoring sites. 

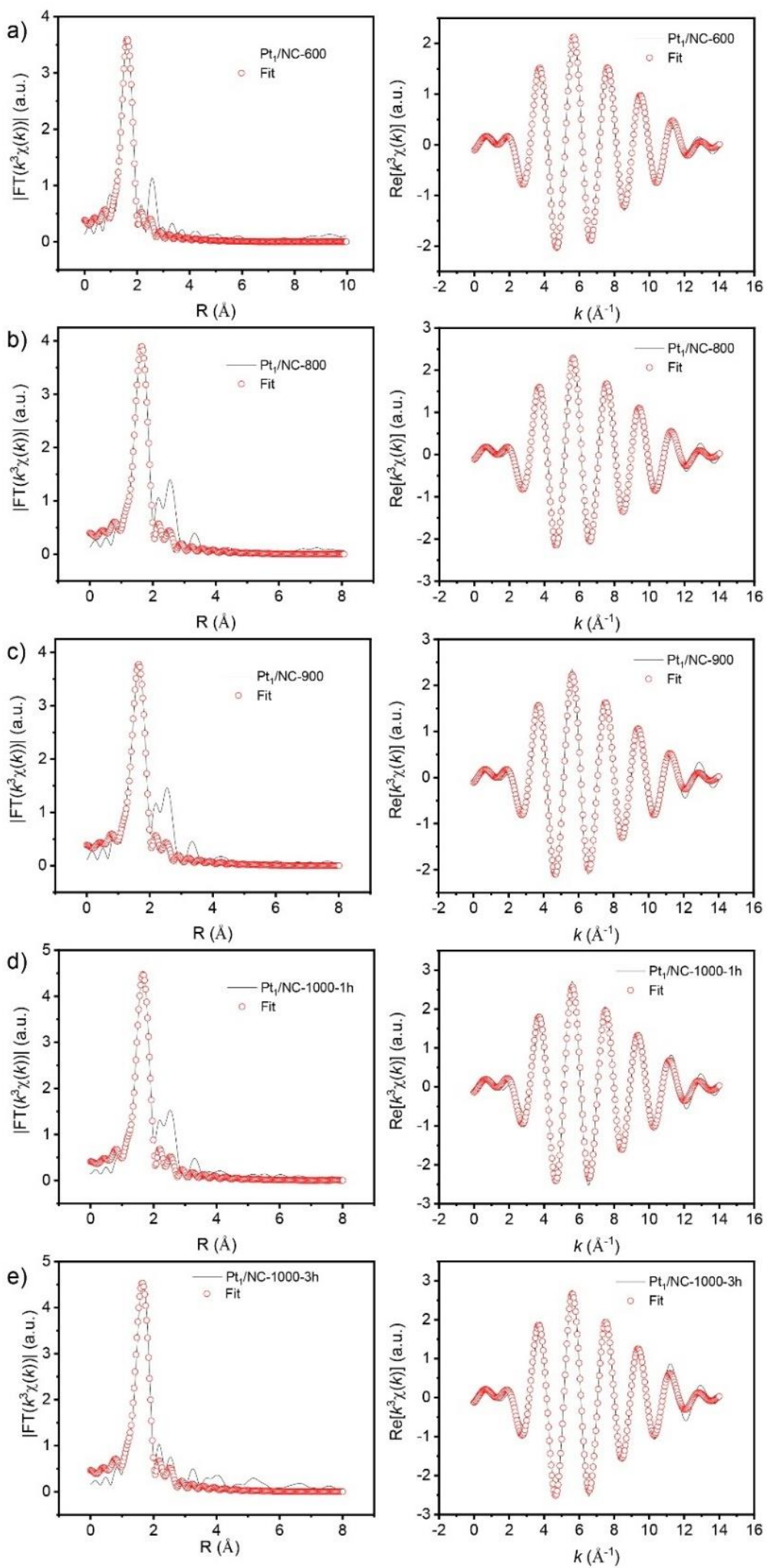

Figure S11. The Fourier transforms EXAFS fitting results in $R$-Space and k3-weighted EXAFS oscillations of (a) $\mathrm{Pt}_{1} / \mathrm{NC}-600$, (b) $\mathrm{Pt}_{1} / \mathrm{NC}-800$, (c) $\mathrm{Pt}_{1} / \mathrm{NC}-900$, (d) $\mathrm{Pt}_{1} / \mathrm{NC}$ 1000-1h and (e) $\mathrm{Pt}_{1} / \mathrm{NC}-1000-3 \mathrm{~h}$ respectively at $\mathrm{Pt}_{\mathrm{3}}$-edge. 

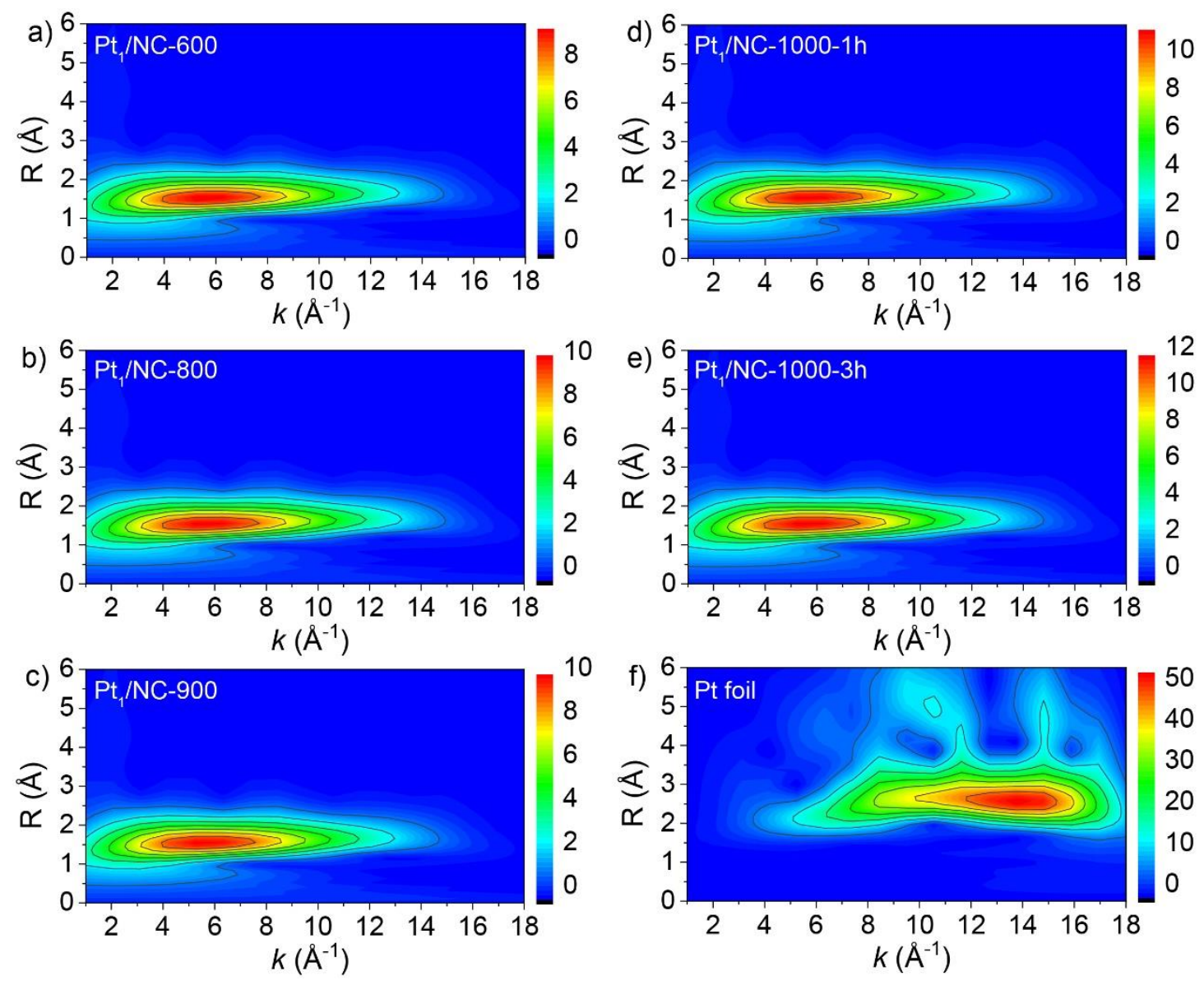

Figure S12. $\mathrm{Pt} L_{3}$-edge WT-EXAFS contour plots of (a) $\mathrm{Pt}_{1} / \mathrm{NC}-600$, (b) $\mathrm{Pt}_{1} / \mathrm{NC}-800$, (c) $\mathrm{Pt}_{1} / \mathrm{NC}-900$, (d) $\mathrm{Pt}_{1} / \mathrm{NC}-1000-1 \mathrm{~h}$, (e) $\mathrm{Pt}_{1} / \mathrm{NC}-1000-3 \mathrm{~h}$ and (f) $\mathrm{Pt}$ foil respectively.

\section{Supporting Notes:}

In the EXAFS spectra of $\mathrm{Pt}_{1}$ SACs (Fig. 2c), The weak peak at $2.50 \AA$ was attributed to Pt-N/C rather than Pt-Pt bonds are due to the following two reasons: (a) The weak peak is at $2.50 \AA$, quite different from the Pt-Pt coordination at $2.65 \AA$ according to the Pt foil reference spectrum. (b) Wavelet transform (WT) map of $\mathrm{Pt}_{1} / \mathrm{NC}$ SACs showed that there was basically one peak at the positions $(R, k)$ of $\left(1.5 \AA, 6.0 \AA^{-1}\right)$ (Figure S12a-e), which is mainly attributed to Pt-N/C coordination. In contrast, for the WT map of Pt foil, the peak position locates at $(2.5$ $\AA, 14 \AA^{-1}$ ) (Figure S12f), which is sharply different from that of $\mathrm{Pt}_{1} / \mathrm{NC} \mathrm{SACs}$. 

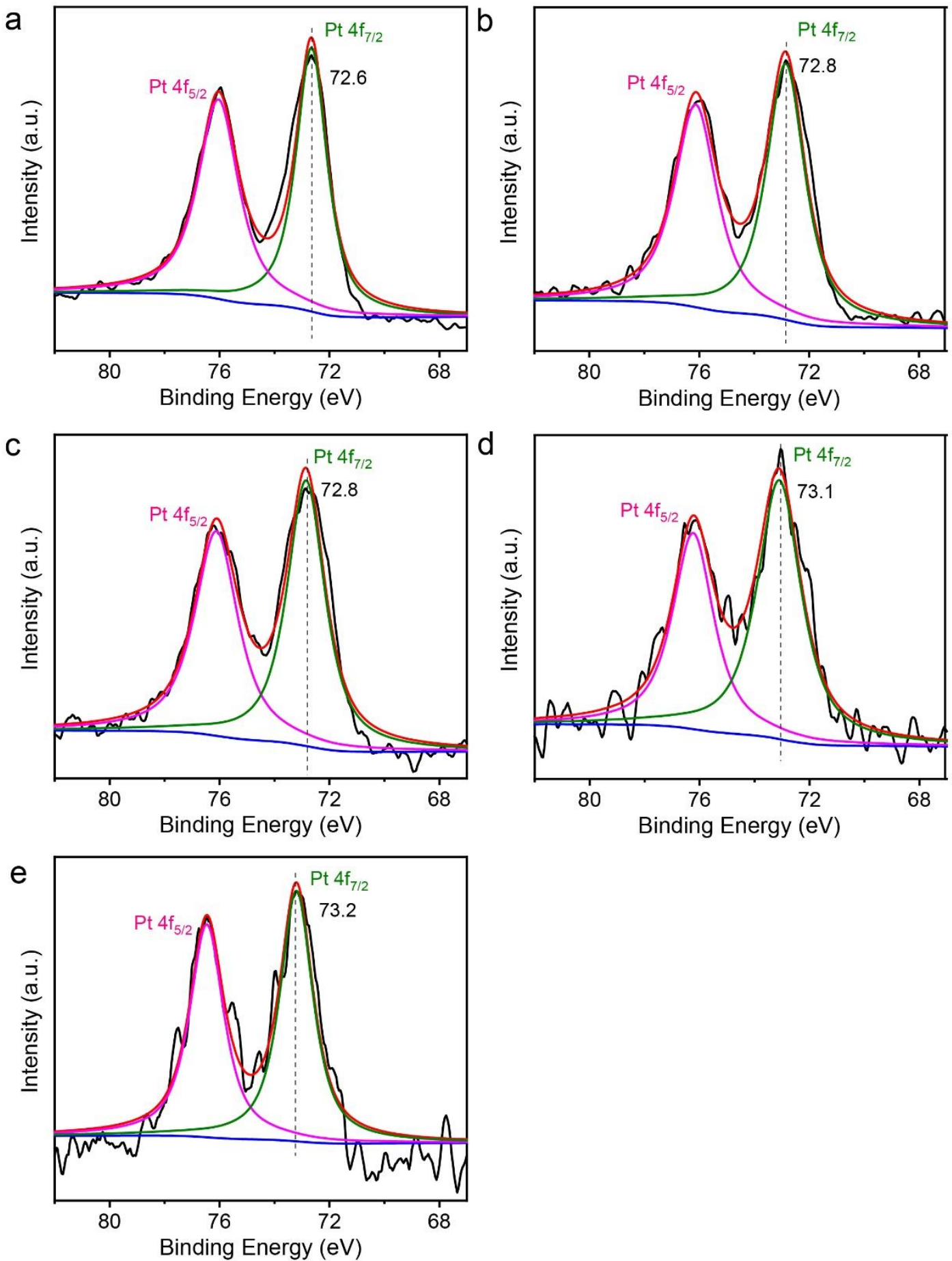

Figure S13. XPS spectra of (a) $\mathrm{Pt}_{1} / \mathrm{NC}-600$, (b) $\mathrm{Pt}_{1} / \mathrm{NC}-800$, (c) $\mathrm{Pt}_{1} / \mathrm{NC}-900$, (d) $\mathrm{Pt}_{1} / \mathrm{NC}-1000-1 \mathrm{~h}$, and (e) $\mathrm{Pt}_{1} / \mathrm{NC}-1000-3 \mathrm{~h}$ in the $\mathrm{Pt} 4$ region along with the peak fittings. 

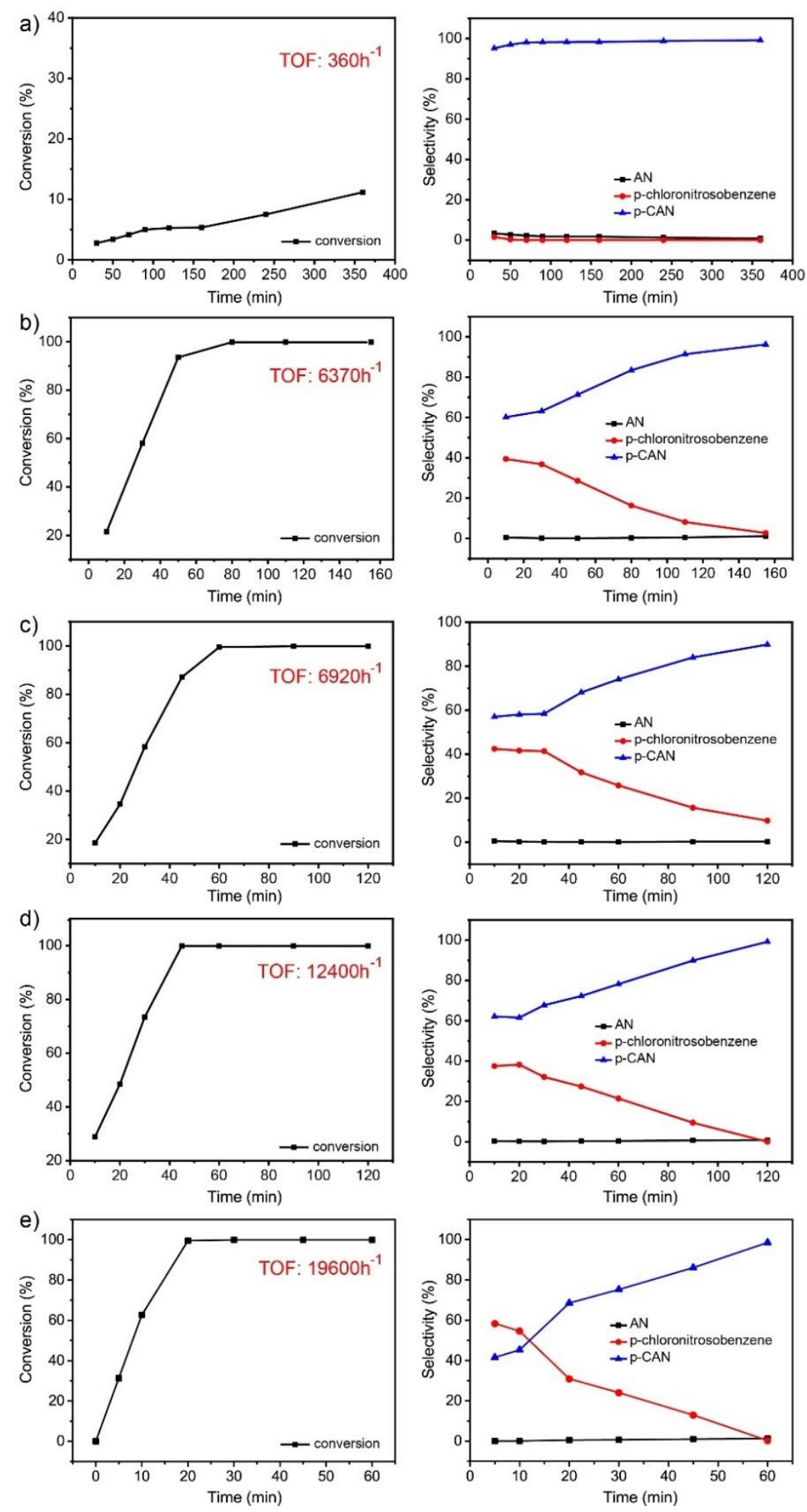

Figure S14. Catalyst performance in terms of conversion and selectivity as a function of reaction time over (a) $\mathrm{Pt}_{1} / \mathrm{NC}-600$, (b) $\mathrm{Pt}_{1} / \mathrm{NC}-800$, (c) $\mathrm{Pt}_{1} / \mathrm{NC}-900$, (d) $\mathrm{Pt}_{1} / \mathrm{NC}-1000$ $1 \mathrm{~h}$ and (e) $\mathrm{Pt}_{1} / \mathrm{NC}-1000-3 \mathrm{~h}$ in hydrogenation of $p$-CNB at $65^{\circ} \mathrm{C}$ and a $\mathrm{H}_{2}$ pressure of 3 bar. 


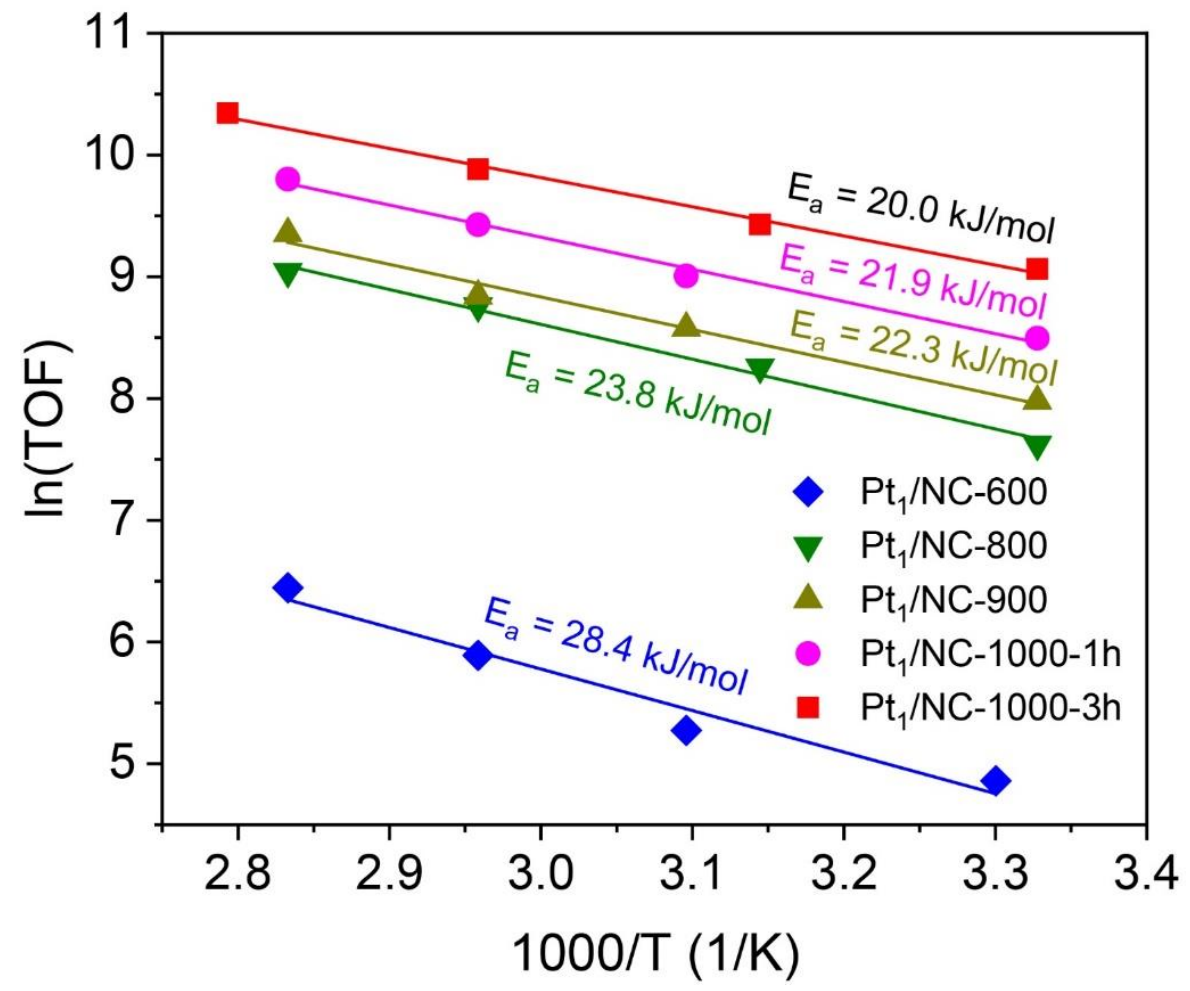

Figure S15. Arrhenius plots for $\mathrm{Pt}_{1} / \mathrm{NC}-600, \mathrm{Pt}_{1} / \mathrm{NC}-800, \mathrm{Pt}_{1} / \mathrm{NC}-900, \mathrm{Pt}_{1} / \mathrm{NC}-1000-$ $1 \mathrm{~h}$ and $\mathrm{Pt}_{1} / \mathrm{NC}-1000-3 \mathrm{~h}$ SACs in hydrogenation of $p$-CNB. 
a)

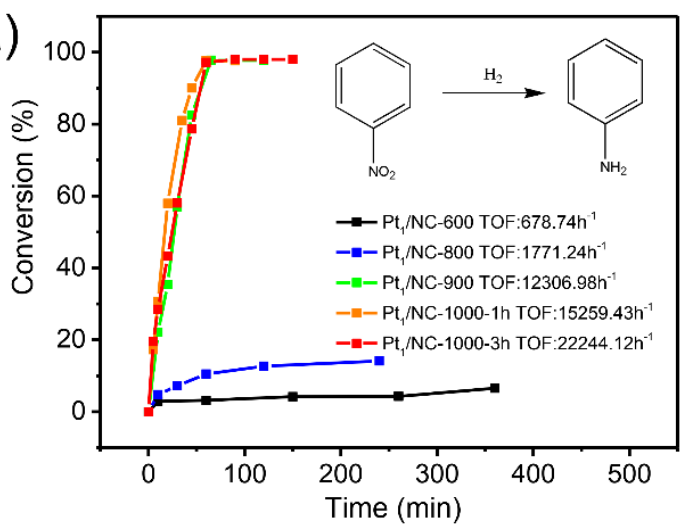

b)

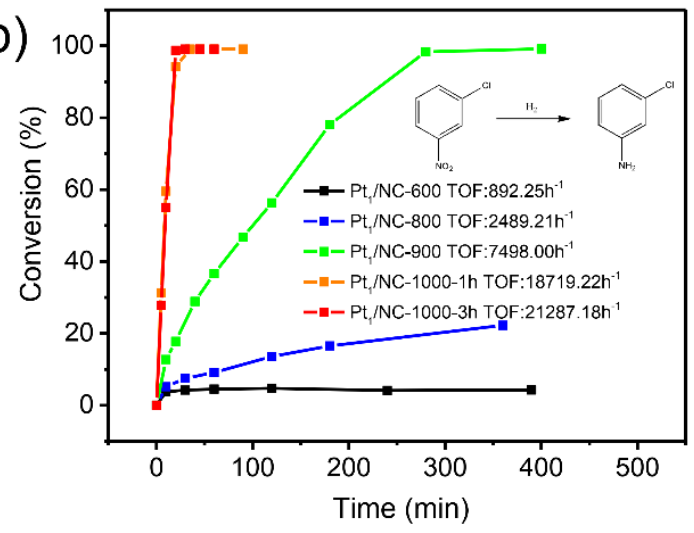

c)

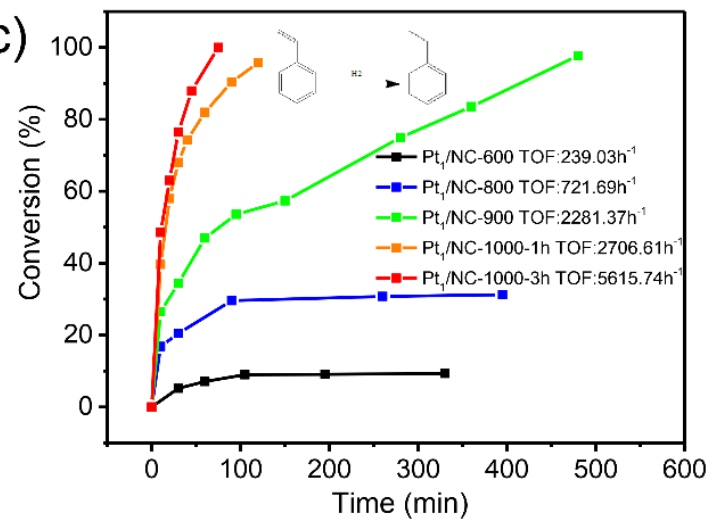

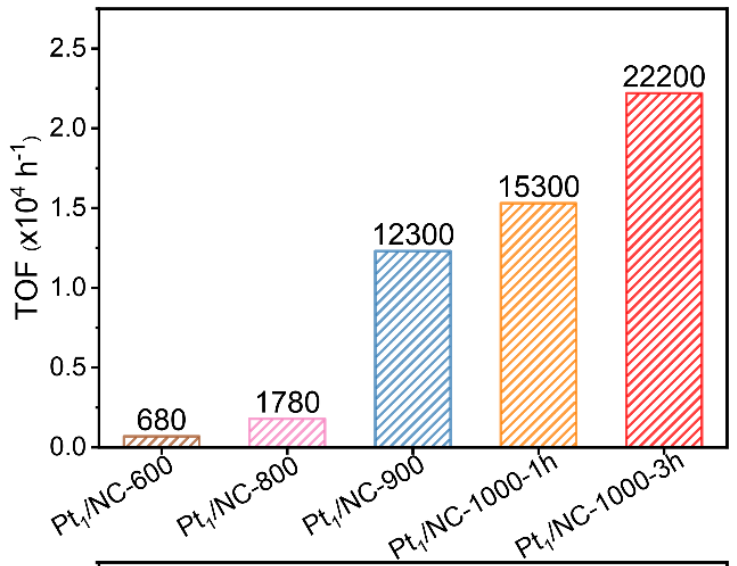
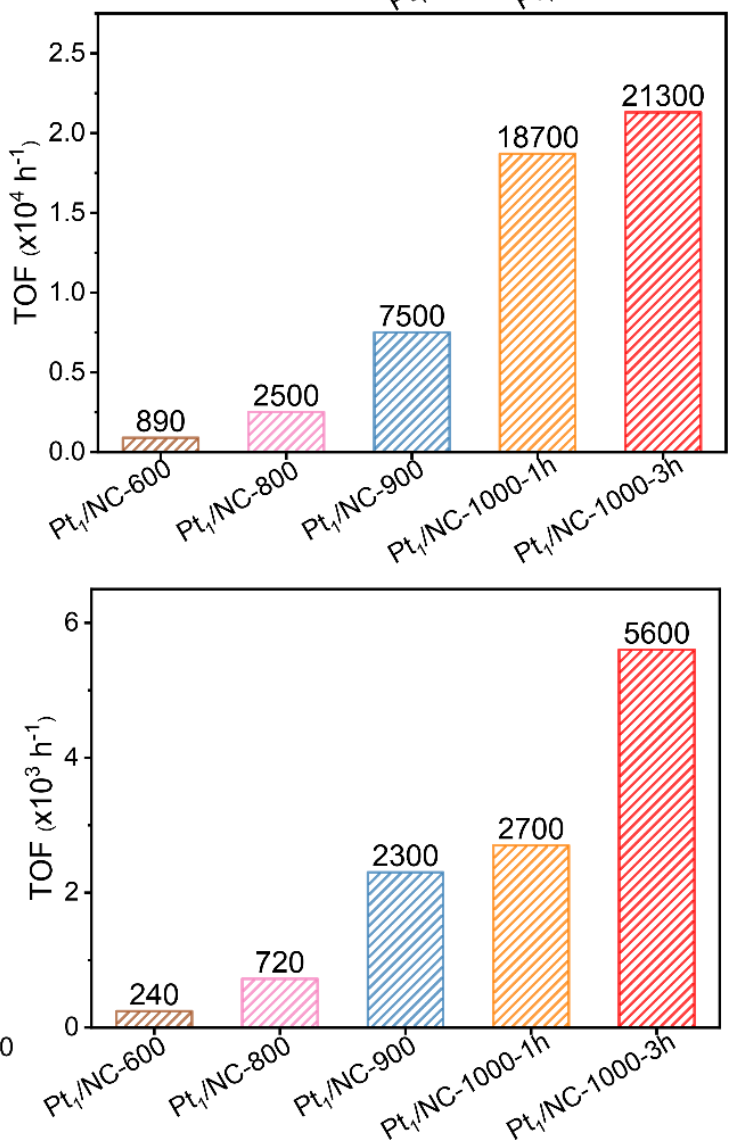

Figure S16. Catalyst performance $\mathrm{Pt}_{1} / \mathrm{NC}$ SACs in hydrogenation of other substrates.

a function of reaction time over Hydrogenation of (a) nitrobenzene, (b) 3Chloronitrobenzene and (c) styrene over. Reaction condition: $65{ }^{\circ} \mathrm{C}, 3 \mathrm{bar} ; 40 \mathrm{ml}$ of ethanol; $2 \mathrm{mmol} 3$-Chloronitrobenzene, or $2 \mathrm{mmol}$ nitrobenzene or $0.4 \mathrm{mmol}$ styrene; The Pt content was normalized to $0.0004 \mathrm{mmol}$. 

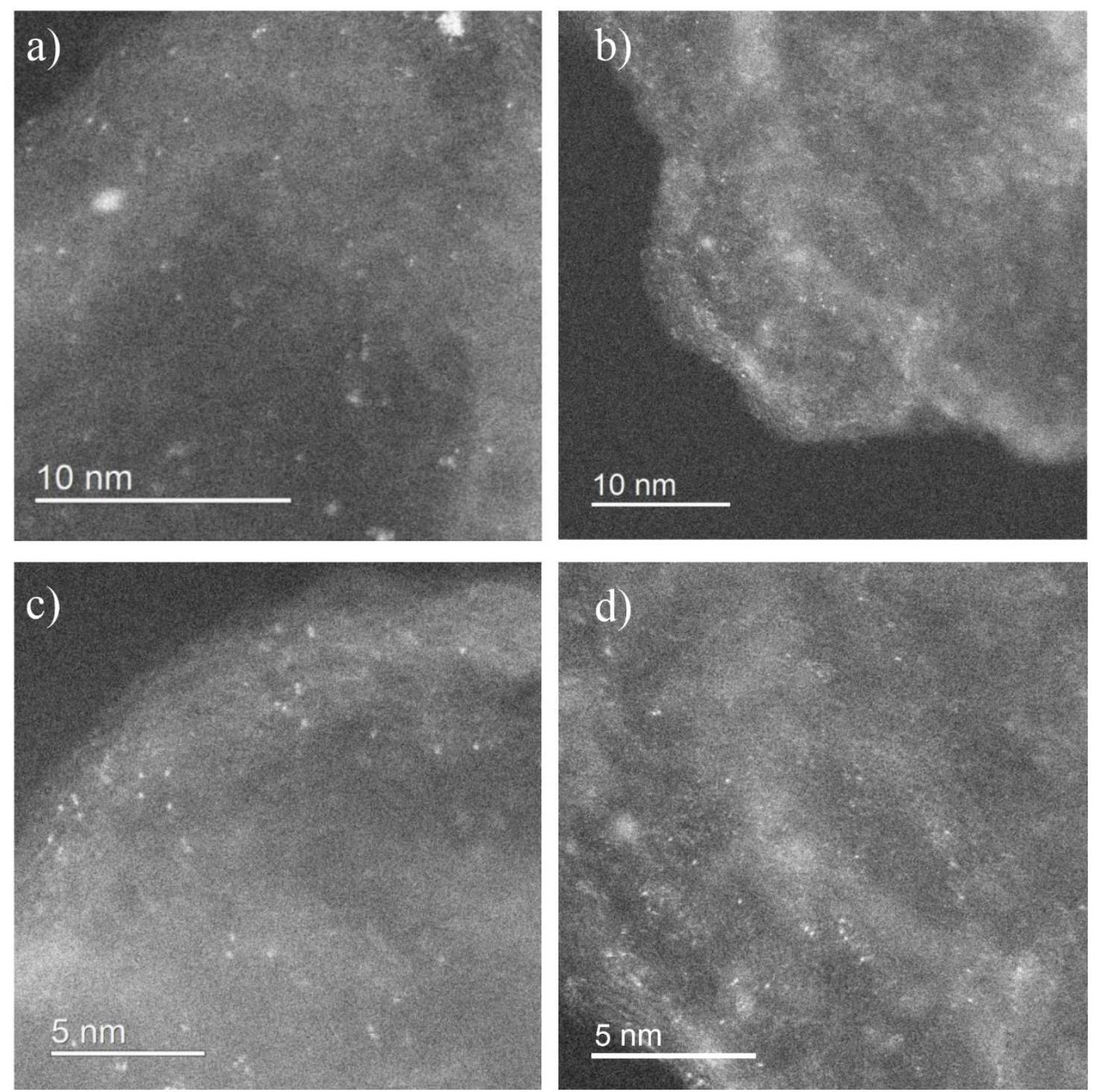

Figure S17. Representative HAADF-STEM images of $\mathrm{Pt}_{1} / \mathrm{NC}-1000-3 \mathrm{~h}$ catalyst after recycling tests at (a,b) low- and (c, d) high-magnifications. 

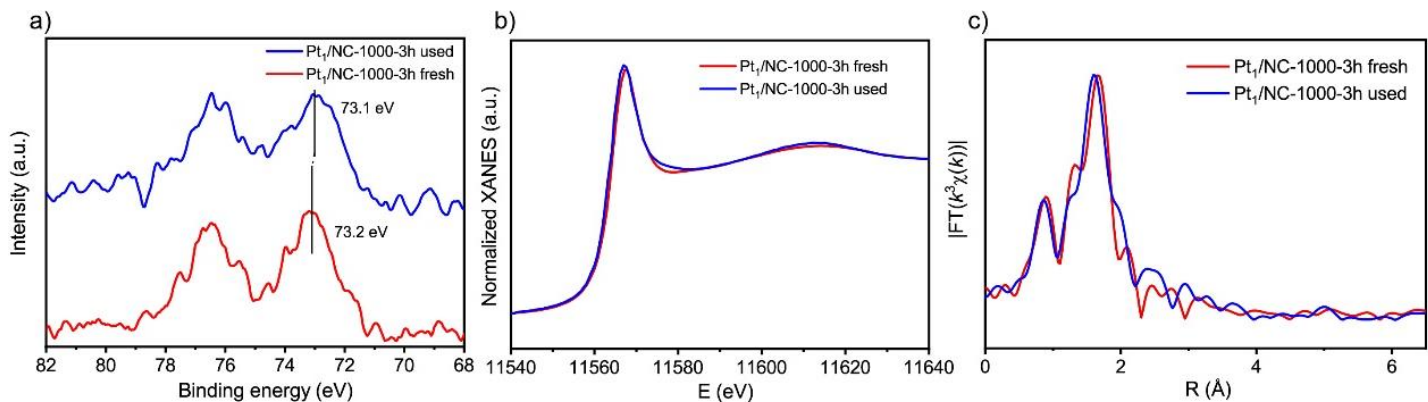

Figure S18. a) XPS spectra of $\mathrm{Pt}_{1} / \mathrm{NC}-1000-3 \mathrm{~h}$ fresh and used catalyst in the $\mathrm{Pt} 4 f$ region. b) XANES spectra of $\mathrm{Pt}_{1} / \mathrm{NC}-1000-3 \mathrm{~h}$ fresh and used catalyst at the $\mathrm{Pt} L_{3}$-edge. c) EXAFS spectra of $\mathrm{Pt}_{1} / \mathrm{NC}-1000-3 \mathrm{~h}$ fresh and used catalyst. 

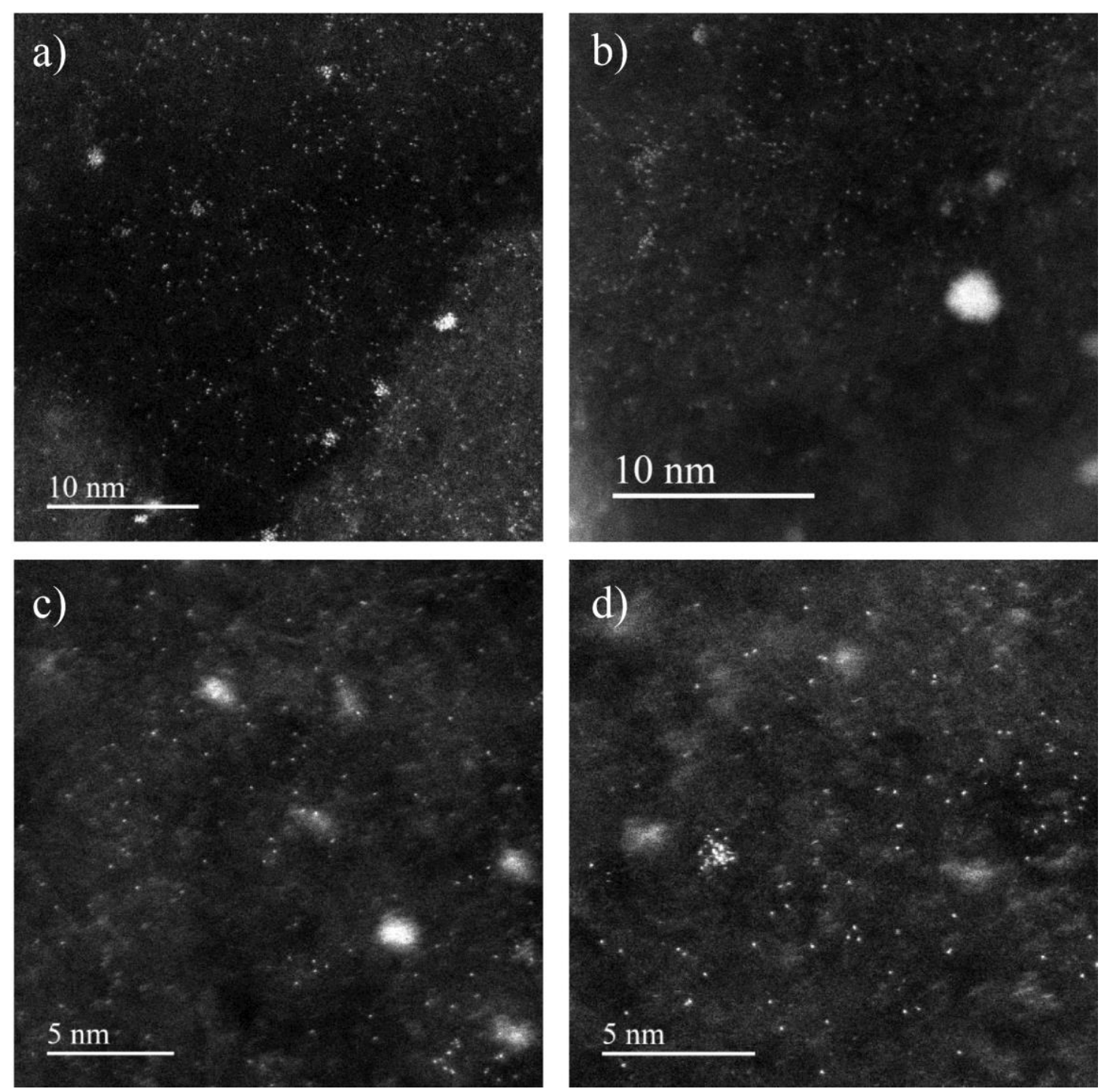

Figure S19. Representative HAADF-STEM images of $\mathrm{Pt}_{1} / \mathrm{NC}-600$ catalyst after recycling tests at (a,b) low- and (c, d) high-magnifications. 

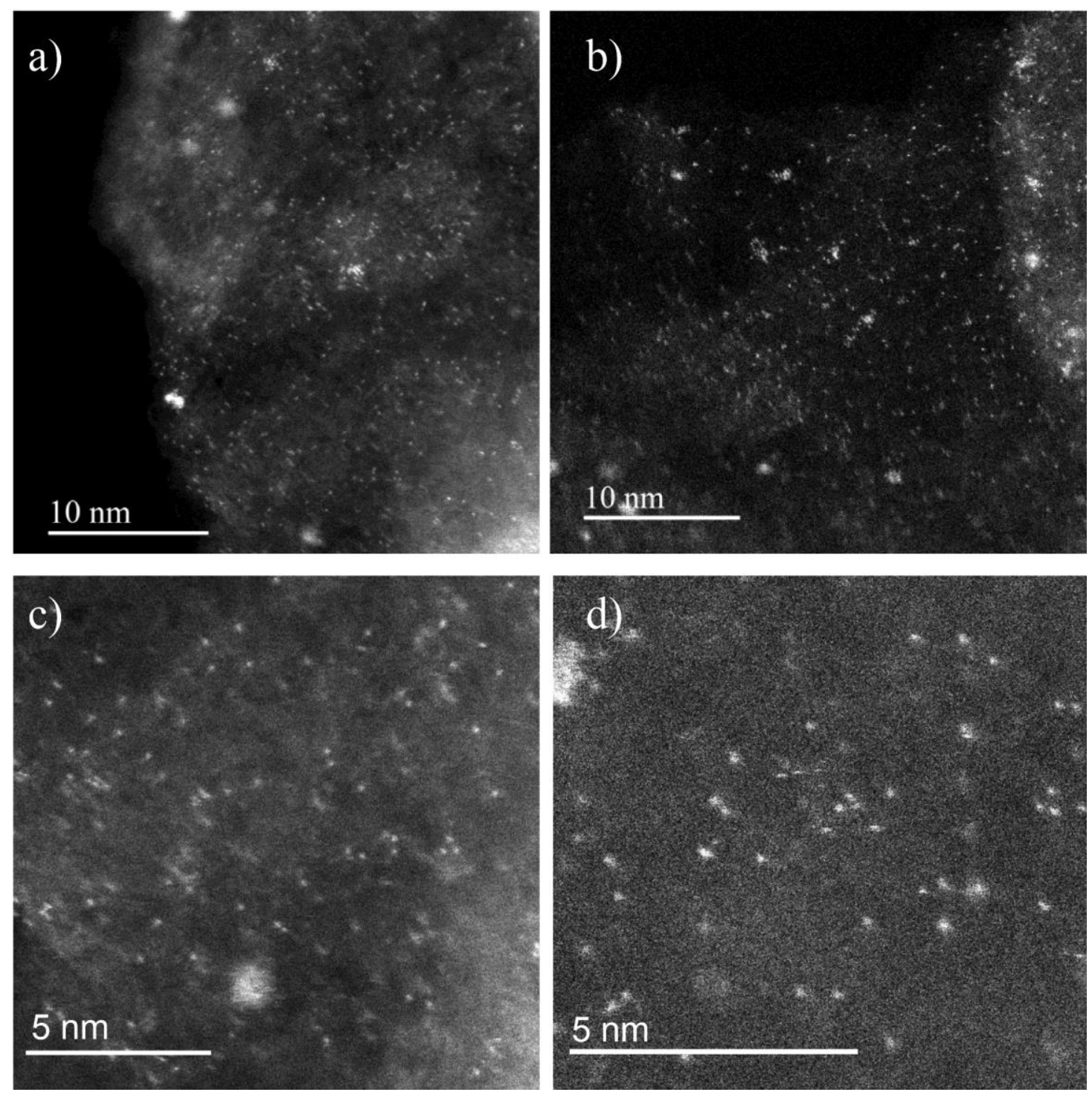

Figure S20. Representative HAADF-STEM images of $\mathrm{Pt}_{1} / \mathrm{NC}-800$ catalyst after recycling tests at (a,b) low- and (c, d) high-magnifications. 

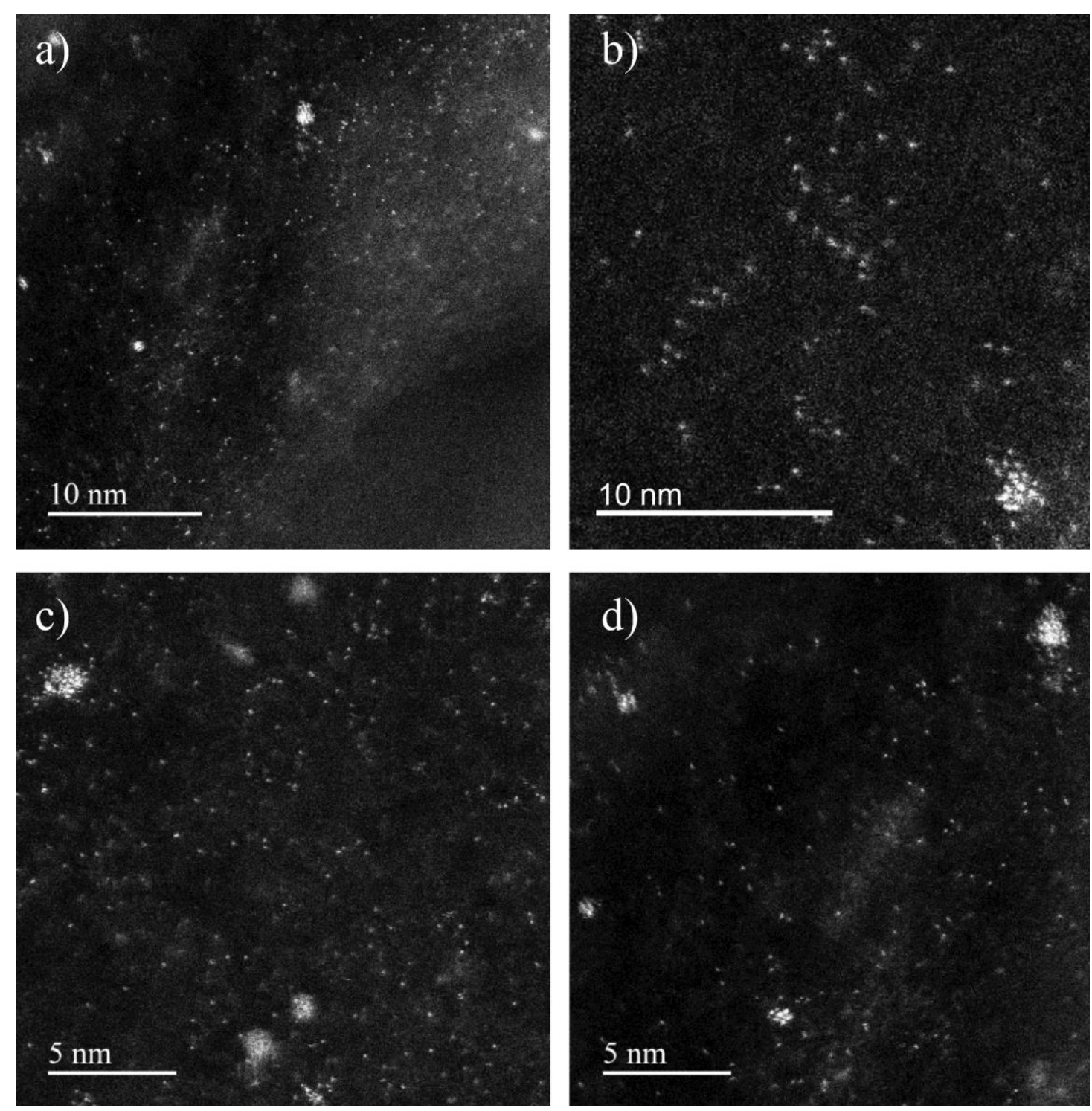

Figure S21. Representative HAADF-STEM images of $\mathrm{Pt}_{1} / \mathrm{NC}-900$ catalyst after recycling tests at $(a, b)$ low- and (c, d) high-magnifications. 

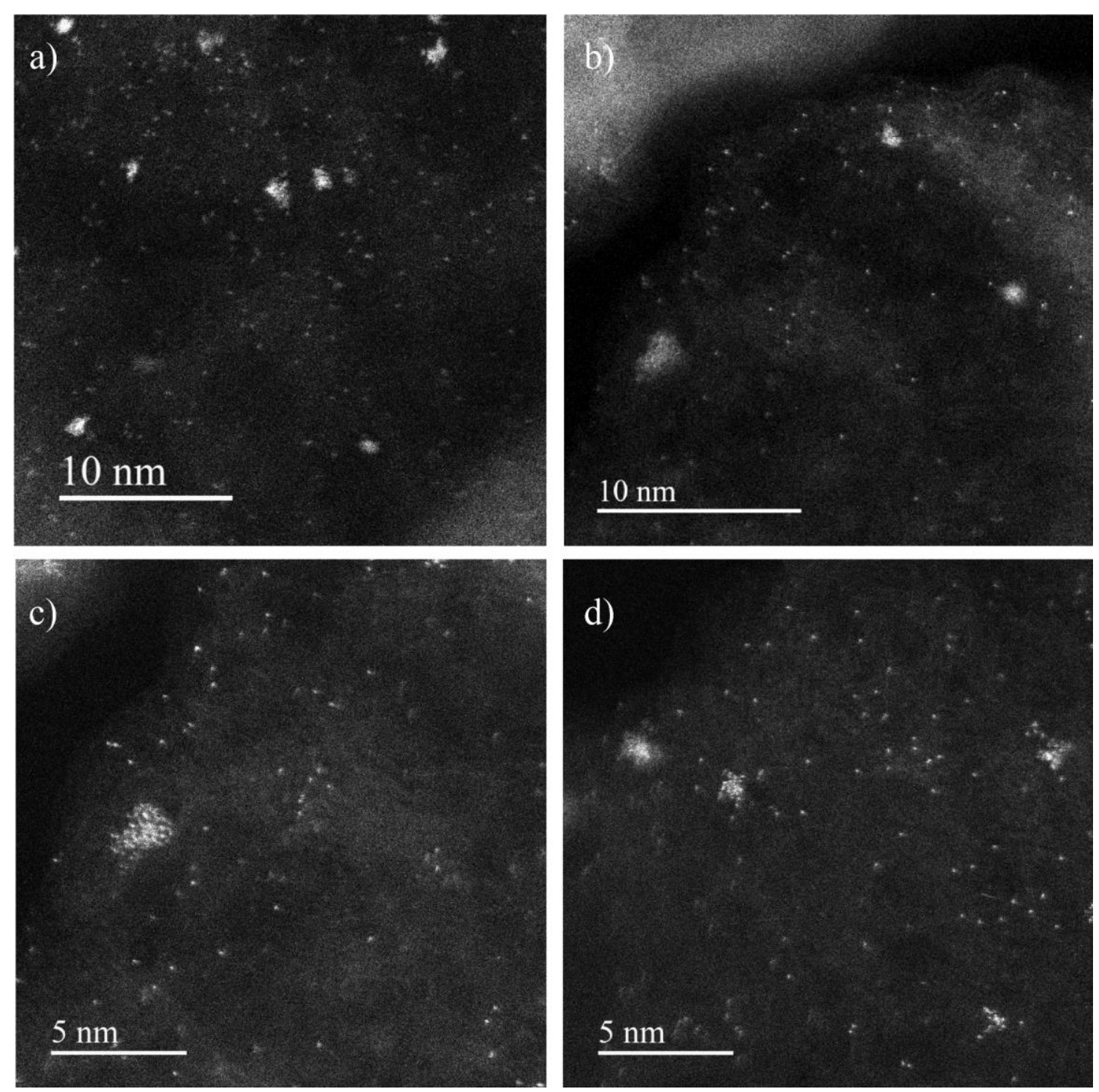

Figure S22. Representative HAADF-STEM images of $\mathrm{Pt}_{1} / \mathrm{NC}-1000-1 \mathrm{~h}$ catalyst after recycling tests at (a,b) low- and (c, d) high-magnifications. 

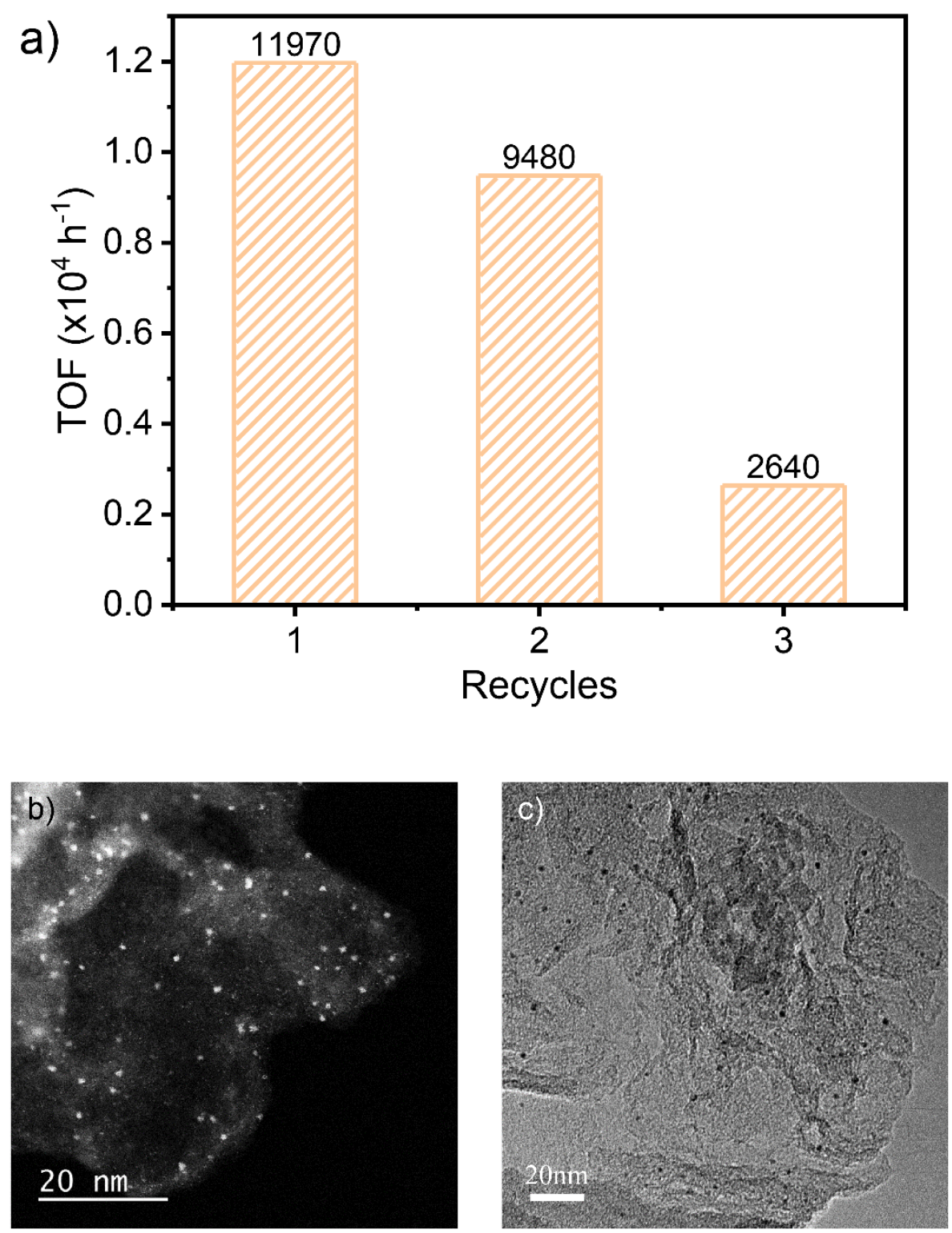

Figure S23. (a) Catalyst recycling test on $\mathrm{Pt} / \mathrm{NC}$ nanoparticles catalyst. (b) The representative HAADF-STEM image of Pt/NC nanoparticles catalyst, scale bar $20 \mathrm{~nm}$. (c) The representative TEM image of $\mathrm{Pt} / \mathrm{NC}$ nanoparticles catalyst after recycling tests, scale bar $20 \mathrm{~nm}$. Reaction condition: $65^{\circ} \mathrm{C}, 3 \mathrm{bar} ; 40 \mathrm{ml}$ of ethanol; $2 \mathrm{mmol} p$-CNB, about $0.0005 \mathrm{mM} \mathrm{Pt}_{1}$ catalysts. 


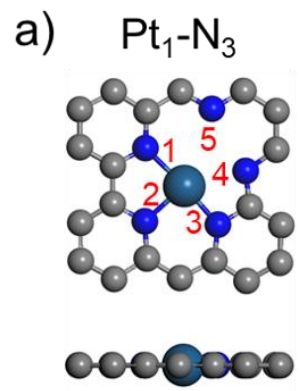

a) $\mathrm{Pt}_{1}-\mathrm{N}_{3}$

b) $\mathrm{Pt}_{1}-\mathrm{N}_{2} \mathrm{C}_{1}$

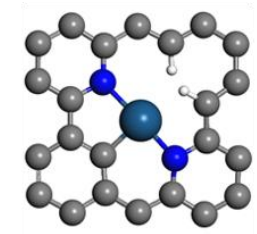

-ocepios c) $\mathrm{Pt}_{1}-\mathrm{N}_{1} \mathrm{C}_{2}$

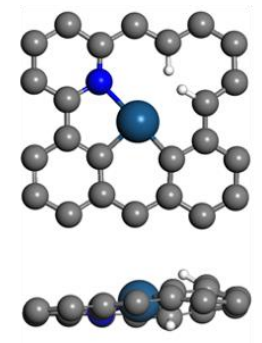

d) $\mathrm{Pt}_{1}-\mathrm{N}_{4}$

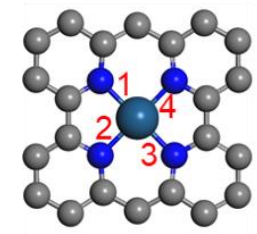

0000000 e) $\mathrm{Pt}_{1}-\mathrm{N}_{3} \mathrm{C}_{1}$

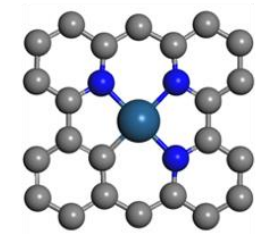

000000 f) $\mathrm{Pt}_{1}-\mathrm{N}_{2} \mathrm{C}_{2}$

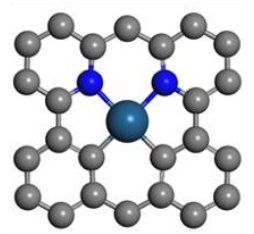

000000 g) $\mathrm{Pt}_{1}-\mathrm{N}_{1} \mathrm{C}_{3}$

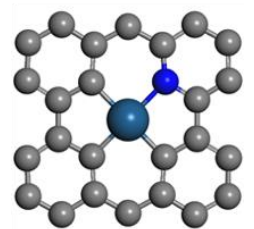

000000

Figure S24. Top and side views of $\mathrm{Pt}_{1} / \mathrm{NC}$ structure models where the coordination number of single $\mathrm{Pt}$ atom is 3: (a) $\mathrm{Pt}_{1}-\mathrm{N}_{3}$, (b) $\mathrm{Pt}_{1}-\mathrm{N}_{2} \mathrm{C}_{1}$, and (c) $\mathrm{Pt}_{1}-\mathrm{N}_{1} \mathrm{C}_{2}$. Alternate model structures where the coordination number of single $\mathrm{Pt}$ atom is 4: (d) $\mathrm{Pt}_{1}-\mathrm{N}_{4}$, (e) $\mathrm{Pt}_{1}-\mathrm{N}_{3} \mathrm{C}_{1}$, (f) $\mathrm{Pt}_{1}-\mathrm{N}_{2} \mathrm{C}_{2}$, (g) $\mathrm{Pt}_{1}-\mathrm{N}_{1} \mathrm{C}_{3}$. Top views on top and side views on bottom. Color code: grey $=\mathrm{C}$, cyan $=\mathrm{Pt}$, blue $=\mathrm{N}$, white $=$ pre-adsorbed $\mathrm{H}$ 

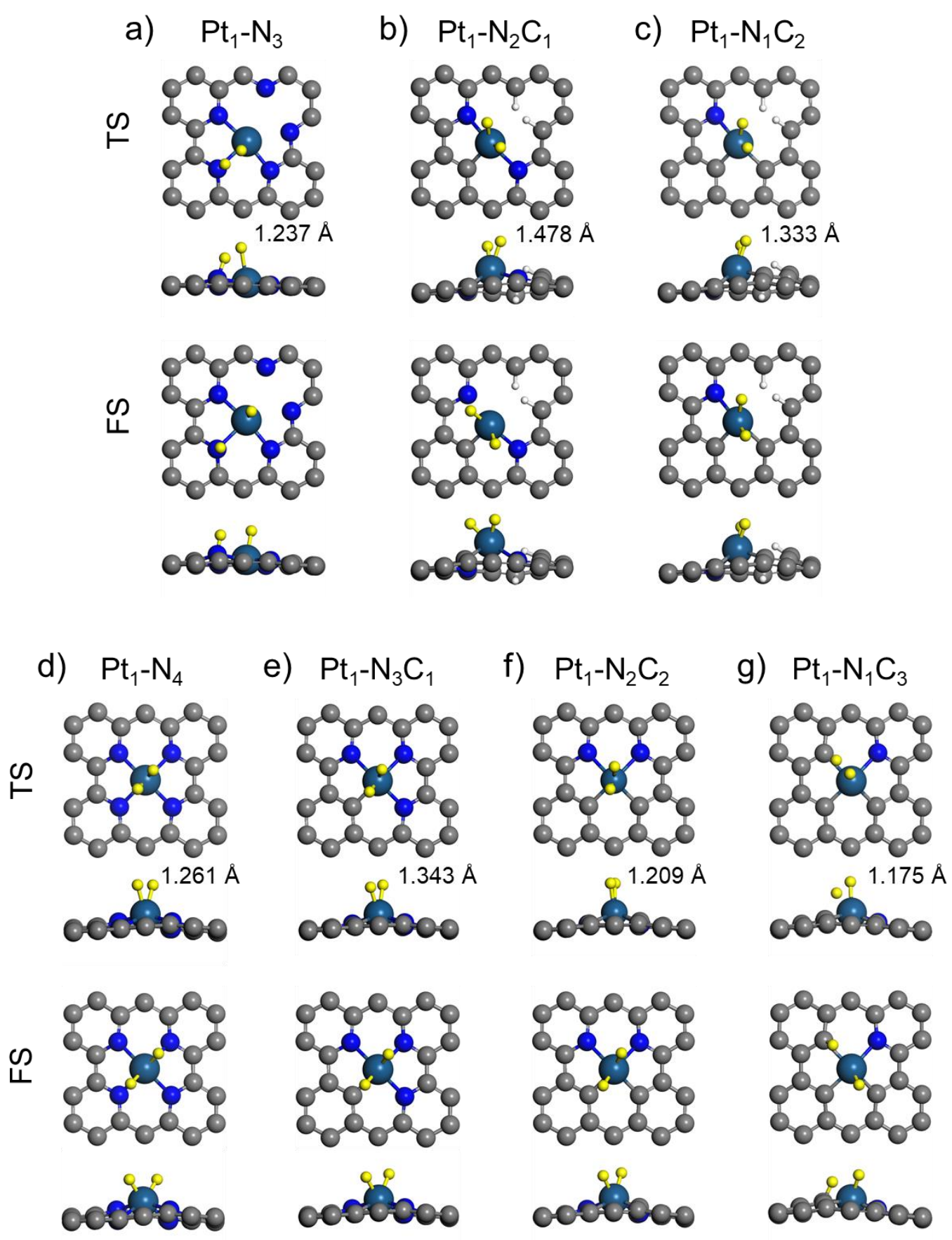

Figure S25. Transition states and corresponding final states for $\mathrm{H}_{2}$ dissociation on model surfaces: (a) $\mathrm{Pt}_{1}-\mathrm{N}_{3}$, (b) $\mathrm{Pt}_{1}-\mathrm{N}_{2} \mathrm{C}_{1}$, (c) $\mathrm{Pt}_{1}-\mathrm{N}_{1} \mathrm{C}_{2}$, (d) $\mathrm{Pt}_{1}-\mathrm{N}_{4}$, (e) $\mathrm{Pt}_{1}-\mathrm{N}_{3} \mathrm{C}_{1}$, (f) $\mathrm{Pt}_{1}-$ $\mathrm{N}_{2} \mathrm{C}_{2}$ and $(\mathrm{g}) \mathrm{Pt}_{1}-\mathrm{N}_{1} \mathrm{C}_{3}$. Top views on top and side views on bottom. Color code: grey $=$ $\mathrm{C}$, cyan $=\mathrm{Pt}$, blue $=\mathrm{N}$, white $=\mathrm{H}$ (pre-adsorbed) and yellow $=\mathrm{H}$. The $\mathrm{H}-\mathrm{H}$ distances in the transition states are labeled. 
a)

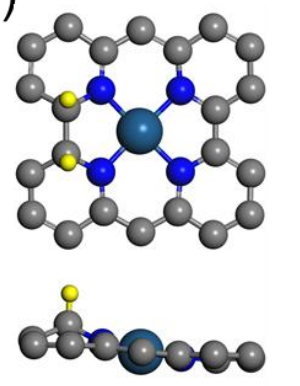

b)

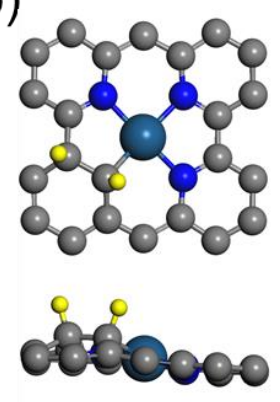

c)

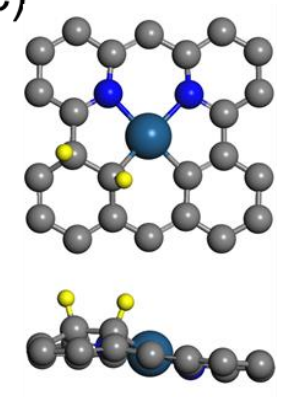

d)

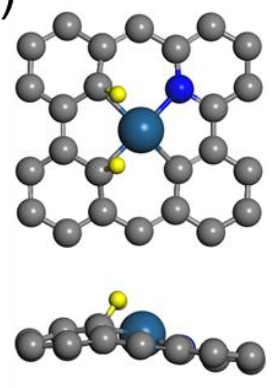

Figure S26. Global minimum state of a pair of dissociated $\mathrm{H}^{*}$ on model surfaces where $\mathrm{CN}\left(\mathrm{Pt}_{1}\right)=$ 4: (a) $\mathrm{Pt}_{1}-\mathrm{N}_{4}$, (b) $\mathrm{Pt}_{1}-\mathrm{N}_{3} \mathrm{C}_{1}$, (c) $\mathrm{Pt}_{1}-\mathrm{N}_{2} \mathrm{C}_{2}$, (d) $\mathrm{Pt}_{1}-\mathrm{N}_{1} \mathrm{C}_{3}$. Top views on top and side views on bottom. Color code: grey $=\mathrm{C}$, cyan $=\mathrm{Pt}$, blue $=\mathrm{N}$, yellow $=\mathrm{H}$. With respect to the corresponding immediate final states (local minimum) of $\mathrm{H}_{2}$ dissociation as shown in Figure. S24 above, global minimum state lowers the dissociative adsorption energies by $1.22 \mathrm{eV}\left(\mathrm{Pt}_{1}-\mathrm{N}_{4}\right), 0.84 \mathrm{eV}\left(\mathrm{Pt}_{1}-\mathrm{N}_{3} \mathrm{C}_{1}\right),-0.11 \mathrm{eV}\left(\mathrm{Pt}_{1}-\mathrm{N}_{2} \mathrm{C}_{2}\right)$ and $0.09 \mathrm{eV}\left(\mathrm{Pt}_{1}-\right.$ $\left.\mathrm{N}_{1} \mathrm{C}_{3}\right)$. 
a)

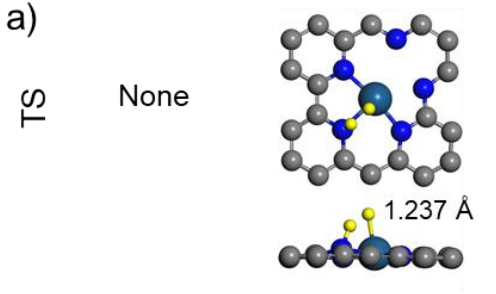

None

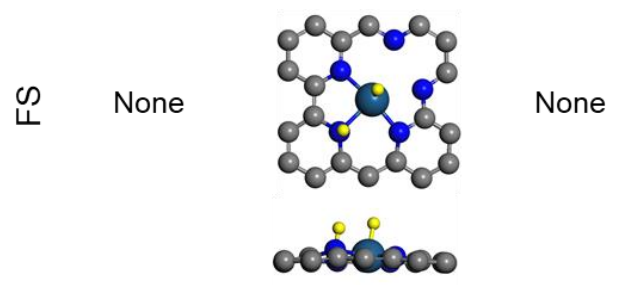

c)

œ
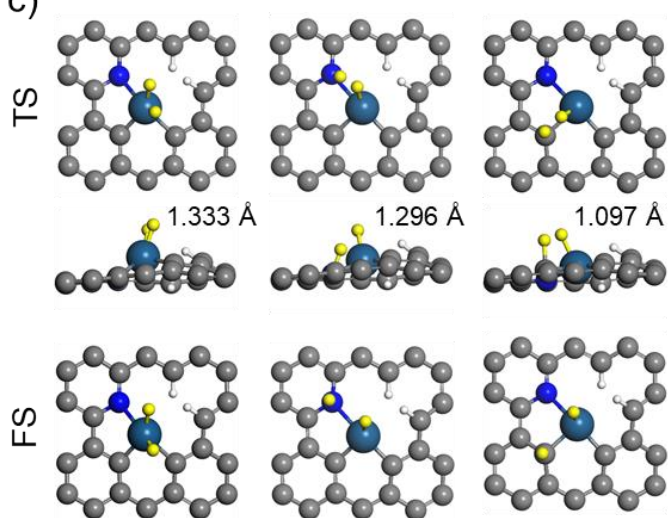
o.ciseo

Homolytic path

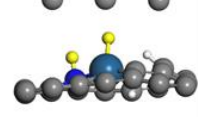

Heterolytic path 1
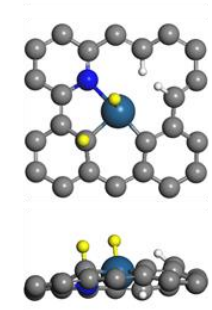

b)
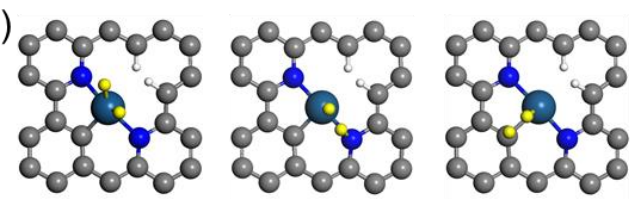

$1.213 \AA$

$1.130 \AA$
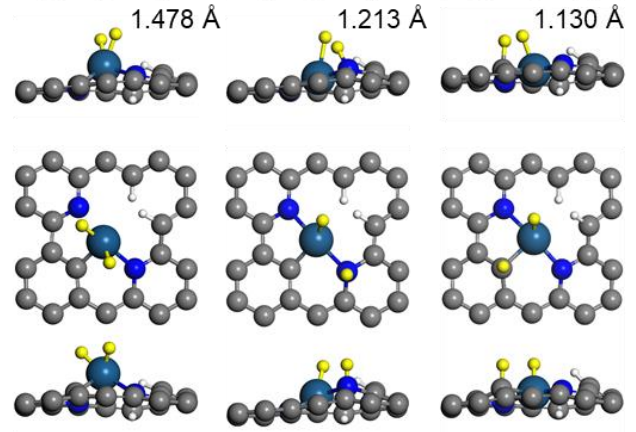

Figure S27. Optimized geometries of transition states and corresponding final states in homolytic path and heterolytic path 1 (via Pt-N pair) and 2 (via Pt-C pair) for $\mathrm{H}_{2}$ dissociation on 3-coordinated a) $\mathrm{Pt}_{1}-\mathrm{N}_{3}$, b) $\mathrm{Pt}_{1}-\mathrm{N}_{2} \mathrm{C}_{1}$ and c) $\mathrm{Pt}_{1}-\mathrm{N}_{1} \mathrm{C}_{2}$ model surfaces. 
a)
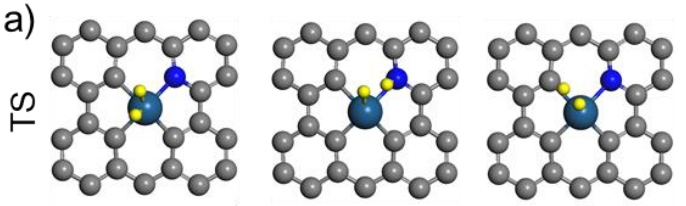

c) $1.124 \AA$ 0000000

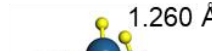

1.175
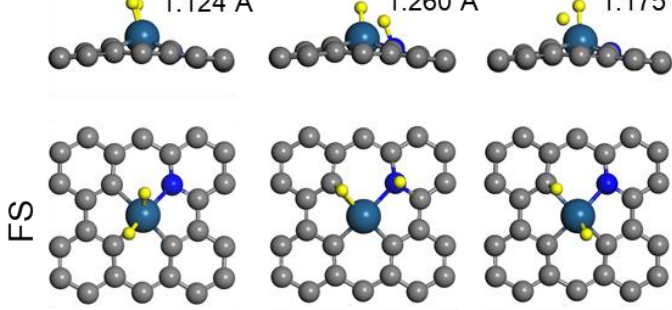
cotione

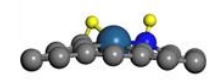

-0000000

c)
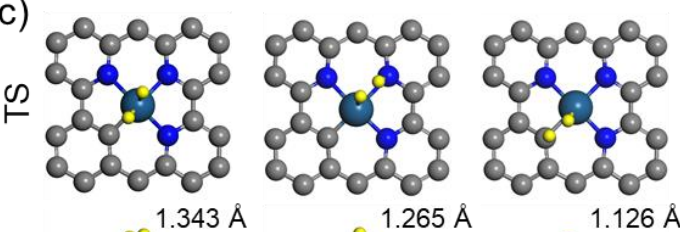

$1.343 \AA$

colbo00
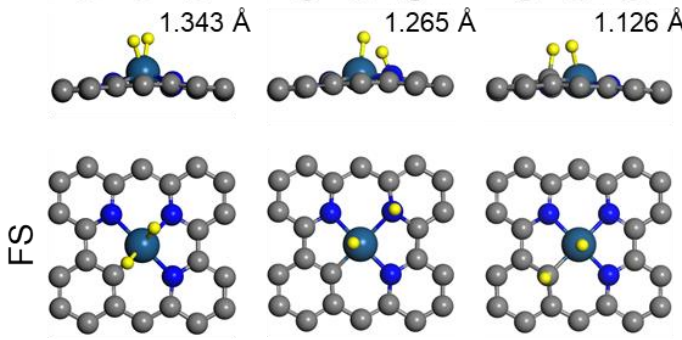

cotbooo

0000000

Homolytic

path
Heterolytic path 1

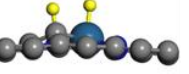

Heterolytic path 2 b)

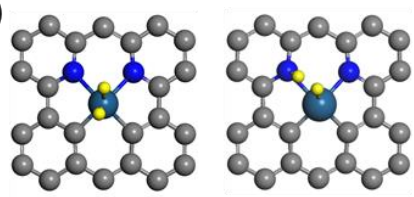

0 $1.209 \AA$ $1.257 \AA$
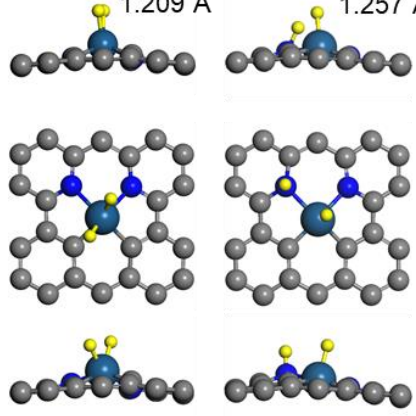

d)
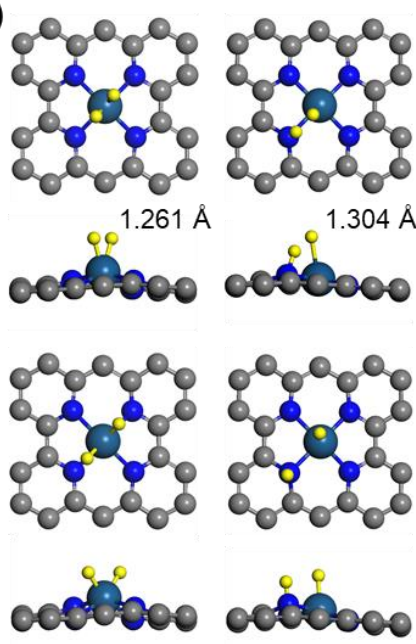

Homolytic Heterolytic path 1
None

None

None

None

Heterolytic

path 2

Figure S28. Optimized geometries of transition states and corresponding final states in homolytic path and heterolytic path 1 (via Pt-N pair) and 2 (via Pt-C pair) for $\mathrm{H}_{2}$ dissociation on 4-coordinated a) $\mathrm{Pt}_{1}-\mathrm{N}_{1} \mathrm{C}_{3}$, b) $\mathrm{Pt}_{1}-\mathrm{N}_{2} \mathrm{C}_{2}$, c) $\mathrm{Pt}_{1}-\mathrm{N}_{3} \mathrm{C}_{1}$ and d) $\mathrm{Pt}_{1}-\mathrm{N}_{4}$ model surfaces. 


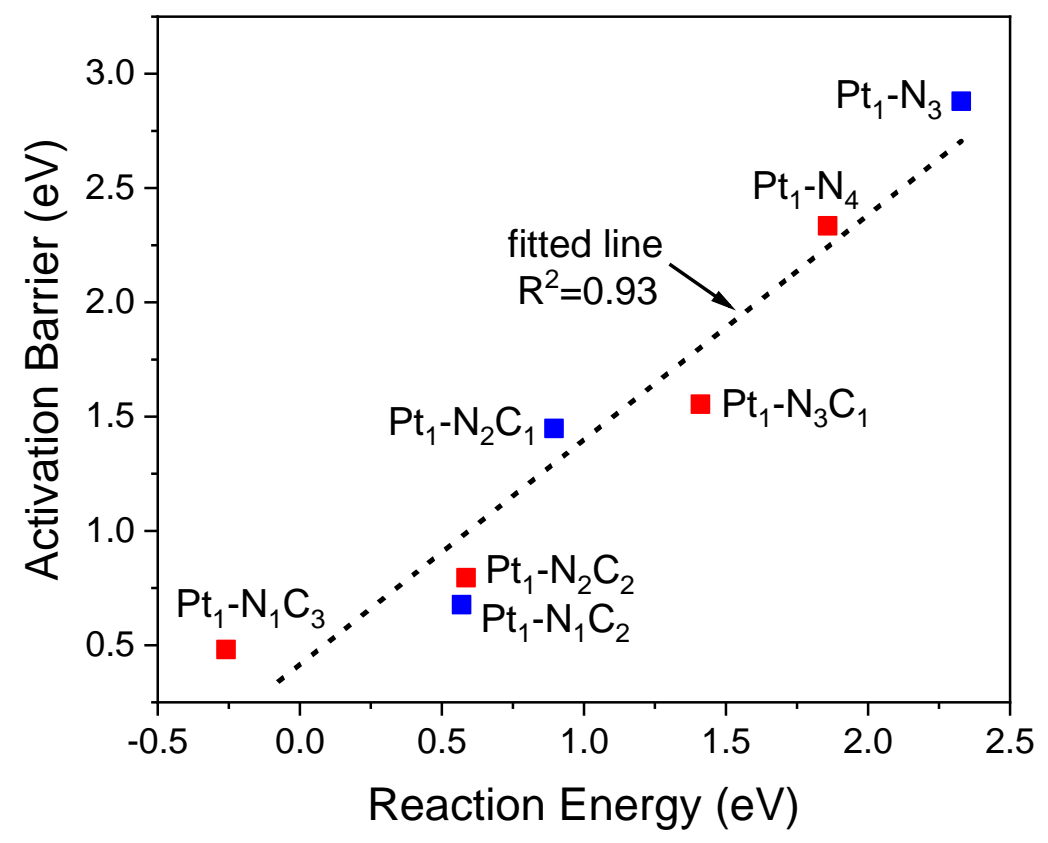

Figure S29. Linear scaling relationship between calculated activation barriers $\left(E_{\mathrm{a}}\right)$ and reaction energies $\left(E_{\mathrm{r}}\right)$ for $\mathrm{H}_{2}$ dissociation on proposed model surfaces. The expression for the fitted line is: $E_{\mathrm{a}}=(0.415 \pm 0.427)+\Delta E_{\mathrm{r}} \cdot(0.982 \pm 0.321)$, where a $95 \%$ confidence level is included. The corresponding $\mathrm{R}^{2}$ value of the fitting is 0.925 . The data points used in generating this plot are available in Table S7 below in bold style. 


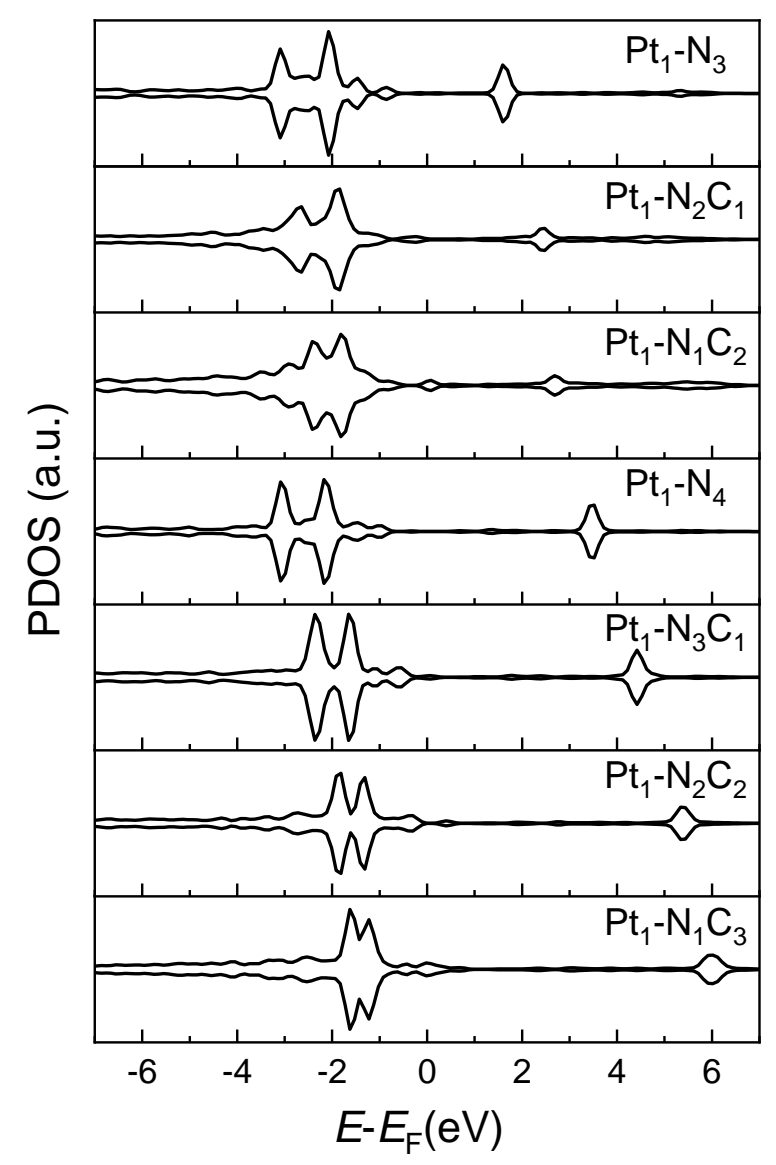

Figure S30. Projected density of states of Pt-5d orbitals in proposed model surfaces. 


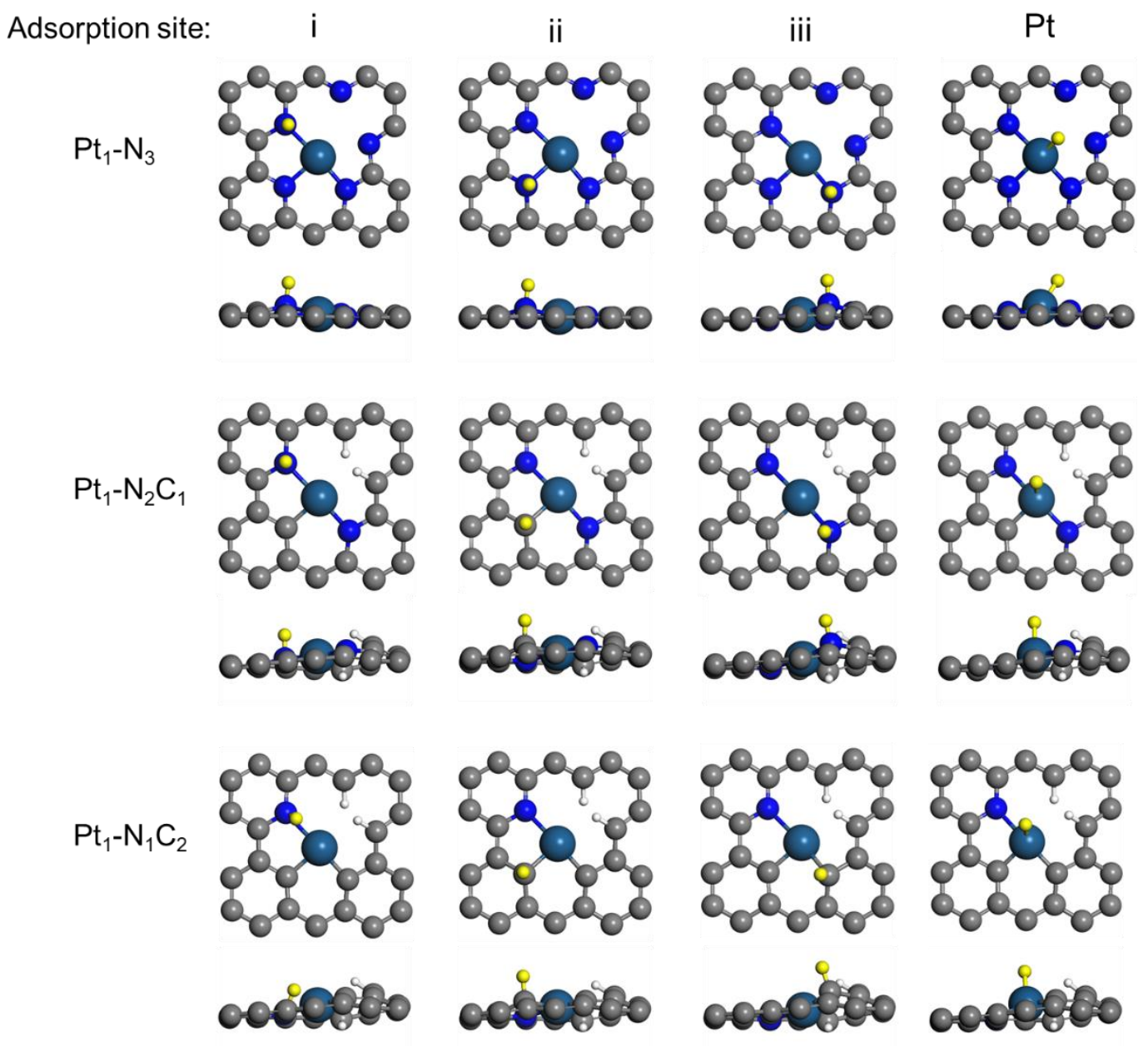

Figure S31. Adsorption geometries of $\mathrm{H}$ atom at $\mathrm{C} / \mathrm{N}$ (i, ii, iii) and $\mathrm{Pt}$ sites on model surfaces where $\mathrm{CN}\left(\mathrm{Pt}_{1}\right)=3$. Color code: grey $=\mathrm{C}$, cyan $=\mathrm{Pt}$, blue $=\mathrm{N}$, white $=\mathrm{H}$ (preadsorbed) and yellow $=\mathrm{H}$. The adsorption energies are in Table S8. 


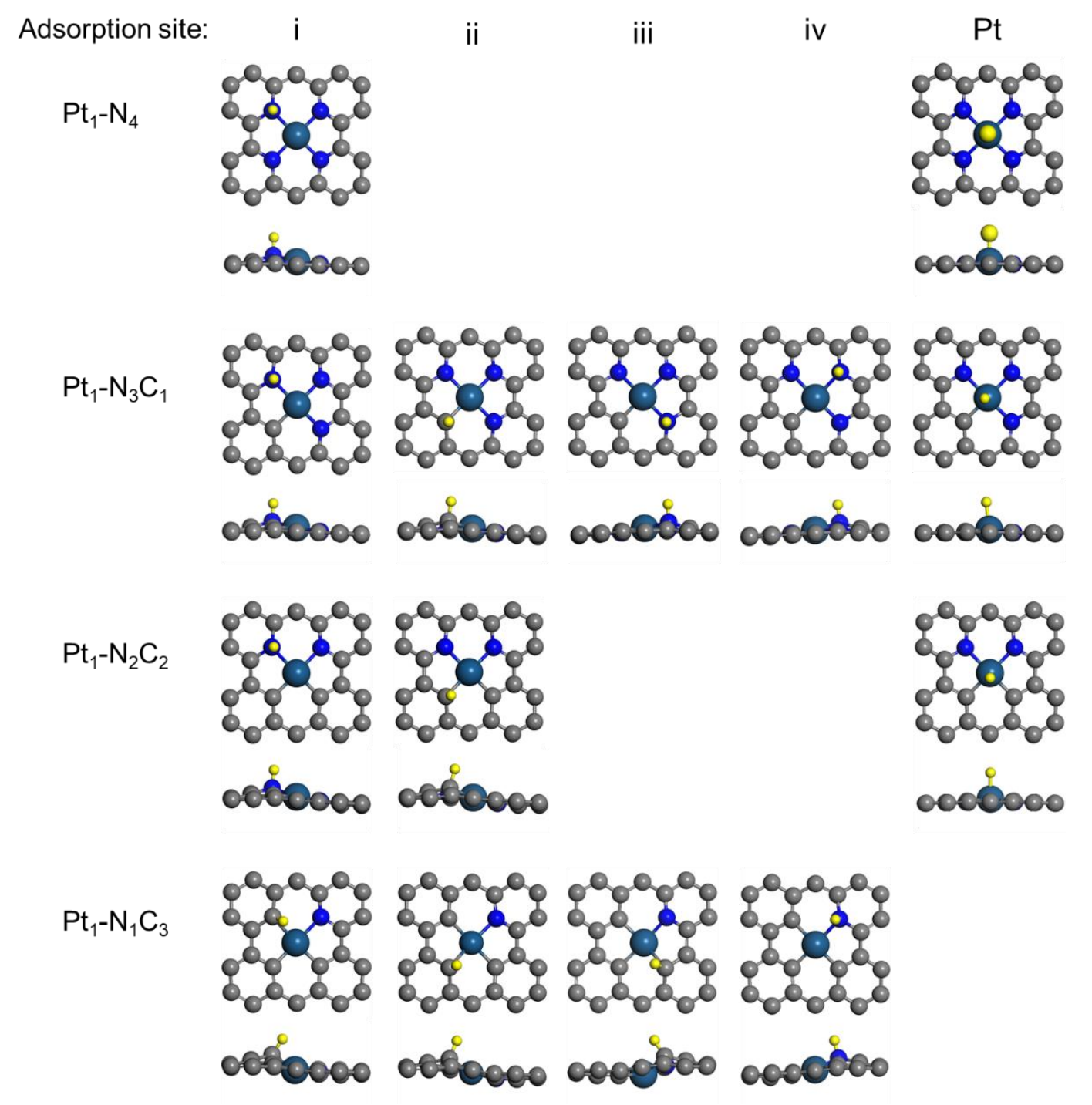

Figure S32. Adsorption geometries of $\mathrm{H}$ atom at $\mathrm{C} / \mathrm{N}$ (i, ii, iii and iv) and $\mathrm{Pt}$ sites on model surfaces where $\mathrm{CN}\left(\mathrm{Pt}_{1}\right)=4$. Color code: grey $=\mathrm{C}$, cyan $=\mathrm{Pt}$, blue $=\mathrm{N}$ and yellow $=\mathrm{H}$. The adsorption energies are in Table S8. 
Table S1. The N contents and types in different NCs as determined by XPS.

\begin{tabular}{ccccc}
\hline Sample & $\begin{array}{c}\text { Total N } \\
(\text { atom\% })\end{array}$ & $\begin{array}{c}\text { Graphitic N } \\
(\text { atom\% })\end{array}$ & $\begin{array}{c}\text { Pyrrolic N } \\
(\text { atom\%) }\end{array}$ & $\begin{array}{c}\text { Pyridinic N } \\
(\text { atom\%) }\end{array}$ \\
\hline $\mathrm{C}_{3} \mathrm{~N}_{4}$ & 48.1 & 5.38 & - & 42.73 \\
NC-600 & 13.86 & 1.41 & 5.55 & 6.90 \\
NC-800 & 11.83 & 3.03 & 4.45 & 4.35 \\
NC-900 & 8.71 & 5.17 & - & 3.54 \\
NC-1000-1h & 5.71 & 4.05 & - & 1.66 \\
\hline NC-1000-3h & 3.47 & 2.90 & - & 0.57 \\
\hline
\end{tabular}


Table S2. The Pt loadings in fresh and used $\mathrm{Pt}_{1} / \mathrm{NC}$ samples as determined by ICPAES.

\begin{tabular}{|c|c|c|c|}
\hline \multirow{2}{*}{ Sample } & \multicolumn{2}{|c|}{ Pt loadings (wt \%) } & \multirow{2}{*}{$\begin{array}{l}\text { Percentages of meta } \\
\qquad \operatorname{loss}(\%)^{\mathbf{b}}\end{array}$} \\
\hline & Fresh samples & Used samples $^{\mathbf{a}}$ & \\
\hline $\mathrm{Pt}_{1} / \mathrm{NC}-600$ & 1.30 & 0.70 & 46 \\
\hline $\mathrm{Pt}_{1} / \mathrm{NC}-800$ & 1.10 & 0.45 & 59 \\
\hline $\mathrm{Pt}_{1} / \mathrm{NC}-900$ & 0.85 & 0.35 & 59 \\
\hline $\mathrm{Pt}_{1} / \mathrm{NC}-1000-1 \mathrm{~h}$ & 0.42 & 0.23 & 45 \\
\hline $\mathrm{Pt}_{1} / \mathrm{NC}-1000-3 \mathrm{~h}$ & 0.34 & 0.30 & 11 \\
\hline
\end{tabular}

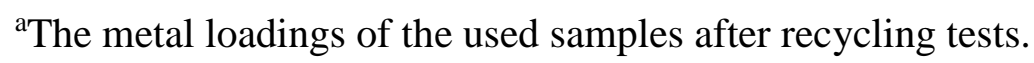

${ }^{b}$ Percentages of metal loss were calculated by the equation:

$$
\text { Percentages of metal loss }=\left(\mathrm{M}_{\text {Fresh }}-\mathrm{M}_{\text {Used }}\right) / \mathrm{M}_{\text {Fresh }} \times 100 \% \text {, }
$$

where $\mathrm{M}_{\text {Fresh }}$ is the metal loadings of the fresh samples, $\mathrm{M}_{\mathrm{Used}}$ is the metal loadings of the used samples 
Table S3. Structural parameters of the $\mathrm{Pt}_{1} / \mathrm{NC}$ SACs from quantitative EXAFS curvefittings using the ARTEMIS module of IFEFFIT.

\begin{tabular}{cccccc}
\hline sample & shell & $\mathbf{N}$ & $\mathbf{R}$ & $\boldsymbol{\sigma}^{\mathbf{2}}\left(\mathbf{1 0}^{-3} \AA^{2}\right)$ & $\boldsymbol{\Delta E}_{\mathbf{0}}(\mathbf{e V})$ \\
\hline $\mathrm{Pt}_{1} / \mathrm{NC}-600$ & $\mathrm{Pt}-\mathrm{N} / \mathrm{C}$ & $3.0 \pm 0.4$ & 2.02 & 6.91 & 9.29 \\
& & & & & \\
$\mathrm{Pt}_{1} / \mathrm{NC}-800$ & $\mathrm{Pt}-\mathrm{N} / \mathrm{C}$ & $3.2 \pm 0.6$ & 2.04 & 6.59 & 9.74 \\
& & & & & \\
$\mathrm{Pt}_{1} / \mathrm{NC}-900$ & $\mathrm{Pt}-\mathrm{N} / \mathrm{C}$ & $3.2 \pm 0.7$ & 2.04 & 7.02 & 10.21 \\
& & & & & \\
$\mathrm{Pt}_{1} / \mathrm{NC}-1000-1 \mathrm{~h}$ & $\mathrm{Pt}-\mathrm{N} / \mathrm{C}$ & $3.4 \pm 0.9$ & 2.05 & 6.09 & 11.07 \\
& & & & & \\
$\mathrm{Pt}_{1} / \mathrm{NC}-1000-3 \mathrm{~h}$ & $\mathrm{Pt}-\mathrm{N} / \mathrm{C}$ & $3.8 \pm 0.3$ & 2.04 & 6.87 & 9.86 \\
\hline
\end{tabular}

CNs, coordination numbers; $\mathrm{R}$, bonding distance; $\sigma^{2}$, Debye-Waller factor; $\Delta \mathrm{E}_{0}$, inner potential shift. 
Table S4. Comparison of catalyst performance of $\mathrm{Pt}_{1} / \mathrm{NC}-1000-3 \mathrm{~h}$ with the representative ones reported in literature in terms of activity in chemoselective hydrogenation of $p$-CNB.

\begin{tabular}{|c|c|c|c|}
\hline Catalyst & Condition & TOF $\left(h^{-1}\right)$ & Reference \\
\hline $\mathrm{Pt}_{1} / \mathrm{NC}-1000-3 \mathrm{~h}$ & $0.3 \mathrm{Mpa} \mathrm{H}_{2}, 65^{\circ} \mathrm{C}$ & 19500 & This work \\
\hline $\mathrm{Pt}_{1} @ \mathrm{C}$ & $0.1 \mathrm{Mpa}_{2}, 40^{\circ} \mathrm{C}$ & 820 & $\operatorname{Ref}^{13}$ \\
\hline $\mathrm{Pt} / \mathrm{RGO}-\mathrm{EG}$ & 1.0Mpa $\mathrm{H}_{2}, 40^{\circ} \mathrm{C}$ & 4577 & $\operatorname{Ref}^{14}$ \\
\hline $\mathrm{Pt} / \mathrm{CNF}-\mathrm{P}$ & 1.0Mpa $\mathrm{H}_{2}, 25^{\circ} \mathrm{C}$ & 815 & $\operatorname{Ref}^{15}$ \\
\hline $\mathrm{Pt} / \mathrm{N}-\mathrm{CNF}-\mathrm{H}$ & 1.0Mpa $\mathrm{H}_{2}, 25^{\circ} \mathrm{C}$ & 212 & $\operatorname{Ref}^{16}$ \\
\hline $0.6 \% \mathrm{Pt}_{1} / \mathrm{CeO}_{2}$ & $1.0 \mathrm{Mpa}_{2}, 40^{\circ} \mathrm{C}$ & 7100 & $\operatorname{Ref}^{17}$ \\
\hline $\mathrm{Pt} / \gamma-\mathrm{Fe} 2 \mathrm{O} 3$ & $0.1 \mathrm{Mpa} \mathrm{H}_{2}, 25^{\circ} \mathrm{C}$ & 3570 & $\operatorname{Ref}^{18}$ \\
\hline KCC-1-PEI/Pt & 1.0Mpa $\mathrm{H}_{2}, 25^{\circ} \mathrm{C}$ & 244 & $\operatorname{Ref}^{19}$ \\
\hline $\mathrm{Pd}_{1} / \alpha-\mathrm{MoC}$ & $0.5 \mathrm{Mpa}_{2}, 60^{\circ} \mathrm{C}$ & 2300 & $\operatorname{Ref}^{20}$ \\
\hline $\mathrm{PtZn} / \mathrm{SiO}_{2}$ & $0.1 \mathrm{Mpa} \mathrm{H}_{2}, 40^{\circ} \mathrm{C}$ & 1350 & $\operatorname{Ref}^{21}$ \\
\hline $\mathrm{Co}_{1} / \mathrm{G}-0.4$ & $0.1 \mathrm{Mpa}_{2}, 25^{\circ} \mathrm{C}$ & 120 & $\operatorname{Ref}^{22}$ \\
\hline
\end{tabular}


Table S5. Interatomic distances ${ }^{\mathrm{a}}$ (in $\AA$ ) between $\mathrm{Pt}_{1}$ and adjacent $\mathrm{C}$ or $\mathrm{N}$ atoms in proposed surface models.

\begin{tabular}{cccccc}
\hline Model & $\mathbf{C N}$ & $\mathbf{d}_{\mathbf{1}}$ & $\mathbf{d}_{\mathbf{2}}$ & $\mathbf{d}_{\mathbf{3}}$ & $\mathbf{d}_{\mathbf{4}}$ \\
\hline $\mathrm{Pt}_{1}-\mathrm{N}_{3}$ & 3 & 2.033 & 1.981 & 1.918 & \\
$\mathrm{Pt}_{1}-\mathrm{N}_{2} \mathrm{C}_{1}$ & 3 & 2.057 & 1.933 & 1.952 & \\
$\mathrm{Pt}_{1}-\mathrm{N}_{1} \mathrm{C}_{2}$ & 3 & 2.110 & 1.927 & 1.912 & \\
$\mathrm{Pt}_{1}-\mathrm{N}_{4}$ & 4 & 1.952 & 1.952 & 1.952 & 1.952 \\
$\mathrm{Pt}_{1}-\mathrm{N}_{3} \mathrm{C}_{1}$ & 4 & & & & \\
& & & & & \\
$\mathrm{Pt}_{1}-\mathrm{N}_{2} \mathrm{C}_{2}$ & 4 & 1.967 & 1.914 & 1.945 & \\
$\mathrm{Pt}_{1}-\mathrm{N}_{1} \mathrm{C}_{3}$ & 4 & 2.011 & 1.905 & 1.905 & 2.010 \\
\hline
\end{tabular}

${ }^{a}$ as illustrated in Figure. S24, $d_{1}$ refers to Pt-N. $d_{2}$ and $d_{3}$ refer to Pt-N or Pt-C. $d_{4}$ refers to Pt-N all $\mathrm{CN}=4$ models. 
Table S6. Formation energies $\left(\Delta E_{\mathrm{f}}\right)$ for $\mathrm{Pt}_{1}-\mathrm{N}_{\mathrm{x}} \mathrm{C}_{\mathrm{y}}$ model surfaces, in $\mathrm{eV}$.

\begin{tabular}{ccc}
\hline Model & CN & Formation energy \\
\hline $\mathrm{Pt}_{1}-\mathrm{N}_{3}$ & 3 & -1.20 \\
$\mathrm{Pt}_{1}-\mathrm{N}_{2} \mathrm{C}_{1}$ & 3 & -1.44 \\
$\mathrm{Pt}_{1}-\mathrm{N}_{1} \mathrm{C}_{2}$ & 3 & -1.25 \\
$\mathrm{Pt}_{1}-\mathrm{N}_{4}$ & 4 & -2.07 \\
$\mathrm{Pt}_{1}-\mathrm{N}_{3} \mathrm{C}_{1}$ & 4 & -2.81 \\
$\mathrm{Pt}_{1}-\mathrm{N}_{2} \mathrm{C}_{2}$ & 4 & -2.54 \\
$\mathrm{Pt}_{1}-\mathrm{N}_{1} \mathrm{C}_{3}$ & 4 & -2.56 \\
\hline
\end{tabular}


Table S7. Comparisons of activation barriers $\left(E_{\mathrm{a}}\right)$ and reaction energies $\left(\Delta E_{\mathrm{r}}\right)$ in homolytic path and heterolytic path 1 (via Pt-N pair) and 2 (via Pt-C pair) for $\mathrm{H}_{2}$ dissociation on these 3- and 4-coordinated $\mathrm{Pt}_{1}-\mathrm{N}_{\mathrm{x}} \mathrm{C}_{\mathrm{y}}$ model surfaces. The corresponding $5 d$-state centers $\left(\varepsilon_{\mathrm{d}}\right)$ of these structures are also listed.

\begin{tabular}{|c|c|c|c|c|c|c|c|c|}
\hline \multirow{2}{*}{$\mathrm{CN}$} & \multirow{2}{*}{ Model } & \multicolumn{2}{|c|}{ Homolytic Path } & \multicolumn{2}{|c|}{$\begin{array}{l}\text { Heterolytic Path } 1 \\
\text { (via Pt-N pair) }\end{array}$} & \multicolumn{2}{|c|}{$\begin{array}{l}\text { Heterolytic Path } 2 \\
\text { (via Pt-C pair) }\end{array}$} & \multirow{2}{*}{$\varepsilon_{\mathrm{d}(\mathrm{eV})}$} \\
\hline & & $E_{\mathrm{a}}(\mathrm{eV})$ & $\Delta E_{\mathrm{r}}(\mathrm{eV})$ & $E_{\mathrm{a}}(\mathrm{eV})$ & $\Delta E_{\mathrm{r}}(\mathrm{eV})$ & $E_{\mathrm{a}}(\mathrm{eV})$ & $\Delta E_{\mathrm{r}}(\mathrm{eV})$ & \\
\hline 3 & $\mathrm{Pt}_{1}-\mathrm{N}_{3}$ & ${ }^{\mathrm{a}}$ & ${ }^{\mathrm{a}}$ & 2.88 & +2.33 & $-{ }^{b}$ & $-{ }^{b}$ & -2.91 \\
\hline 3 & $\mathrm{Pt}_{1}-\mathrm{N}_{2} \mathrm{C}_{1}$ & 1.45 & +0.89 & 2.45 & +1.42 & 2.24 & +1.53 & -2.72 \\
\hline 3 & $\mathrm{Pt}_{1}-\mathrm{N}_{1} \mathrm{C}_{2}$ & 0.68 & +0.57 & 1.68 & +1.50 & 2.05 & +1.11 & -2.62 \\
\hline 4 & $\mathrm{Pt}_{1}-\mathrm{N}_{1} \mathrm{C}_{3}$ & 0.39 & +0.14 & 1.26 & +0.25 & 0.48 & -0.26 & -2.15 \\
\hline 4 & $\mathrm{Pt}_{1}-\mathrm{N}_{2} \mathrm{C}_{2}$ & 0.79 & +0.59 & 1.65 & +1.33 & $-^{\mathrm{a}}$ & $-^{\mathrm{a}}$ & -2.28 \\
\hline 4 & $\mathrm{Pt}_{1}-\mathrm{N}_{3} \mathrm{C}_{1}$ & 1.55 & +1.41 & 2.37 & +1.81 & 2.14 & +1.26 & -2.59 \\
\hline 4 & $\mathrm{Pt}_{1}-\mathrm{N}_{4}$ & 2.33 & +1.86 & 3.23 & +2.40 & $-^{b}$ & $-{ }^{b}$ & -3.12 \\
\hline
\end{tabular}

${ }^{a} \mathrm{H}_{2}$ cannot dissociate in homolytic path on $\mathrm{Pt}_{1}-\mathrm{N}_{3}$ and in heterolytic path 2 via Pt-C pair on $\mathrm{Pt}_{1}-\mathrm{N}_{2} \mathrm{C}_{2}$ surface.

${ }^{b} \mathrm{On} \mathrm{Pt}_{1}-\mathrm{N}_{3}$ and $\mathrm{Pt}_{1}-\mathrm{N}_{4}$ surfaces, $\mathrm{Pt}$ single atom is exclusively coordinated with $\mathrm{N}$ atoms and Pt-C pair does not exist. 
Table S8. Adsorption energies of $\mathrm{H}$ atom at different sites on model surfaces. The energy reference is $1 / 2 \mathrm{H}_{2}(\mathrm{~g})$ in gas phase. The corresponding structures are in Figs. S31 and S32.

\begin{tabular}{|c|c|c|c|c|c|c|}
\hline \multirow{2}{*}{ Model } & \multirow{2}{*}{$\mathrm{CN}$} & \multicolumn{4}{|c|}{$E_{\text {ads }}(\mathrm{eV})$} & \multirow[b]{2}{*}{ Pt } \\
\hline & & $\mathrm{i}$ & ii & iii & iv & \\
\hline $\mathrm{Pt}_{1}-\mathrm{N}_{3}$ & 3 & +0.75 & +1.16 & +1.14 & - & +0.74 \\
\hline $\mathrm{Pt}_{1}-\mathrm{N}_{2} \mathrm{C}_{1}$ & 3 & +1.31 & +0.47 & +0.83 & - & +0.88 \\
\hline $\mathrm{Pt}_{1}-\mathrm{N}_{1} \mathrm{C}_{2}$ & 3 & +1.25 & +0.16 & -0.44 & - & +0.26 \\
\hline $\mathrm{Pt}_{1}-\mathrm{N}_{4}$ & 4 & +1.26 & $-^{\mathrm{a}}$ & $-^{\mathrm{a}}$ & $-^{\mathrm{a}}$ & +1.30 \\
\hline $\mathrm{Pt}_{1}-\mathrm{N}_{3} \mathrm{C}_{1}$ & 4 & +0.88 & +0.19 & +0.73 & +0.83 & +0.53 \\
\hline $\mathrm{Pt}_{1}-\mathrm{N}_{2} \mathrm{C}_{2}$ & 4 & +0.83 & +0.29 & $-^{\mathrm{a}}$ & $-^{\mathrm{a}}$ & +0.40 \\
\hline $\mathrm{Pt}_{1}-\mathrm{N}_{1} \mathrm{C}_{3}$ & 4 & -0.76 & -0.13 & -0.59 & +0.32 & $-{ }^{b}$ \\
\hline
\end{tabular}

${ }^{\mathrm{a}} \mathrm{On} \mathrm{Pt}_{1}-\mathrm{N}_{4}$, the chemical environments of $\mathrm{N}$ (ii) (iii) and (iv) sites are equivalent to that of $\mathrm{N}$ (i) site. Therefore, the adsorptions of $\mathrm{H}$ atom on $\mathrm{N}$ (ii) (iii) and (iv) sites are omitted. Similarly, on $\mathrm{Pt}_{1}-\mathrm{N}_{2} \mathrm{C}_{2}$, the adsorptions of $\mathrm{H}$ atom on $\mathrm{C}$ (iii) and $\mathrm{N}$ (iv) sites are equivalent to those on $\mathrm{C}$ (ii) and $\mathrm{N}$ (i) sites respectively and omitted.

${ }^{\mathrm{b}} \mathrm{On} \mathrm{Pt}_{1}-\mathrm{N}_{1} \mathrm{C}_{3}$, the $\mathrm{H}$ atom binding at top site of $\mathrm{Pt}$ is not stable and will diffuse to $\mathrm{C}$ (i) site during geometry optimization. 


\section{References}

1. Wang, C.; Gu, X.-K.; Yan, H.; Lin, Y.; Li, J.; Liu, D.; Li, W.-X.; Lu, J., WaterMediated Mars - Van Krevelen Mechanism for CO Oxidation on Ceria-Supported Single-Atom $\mathrm{Pt}_{1}$ Catalyst. ACS Catal. 2017, 7 (1), 887-891.

2. Kresse, G.; Furthmuller, J., Efficient iterative schemes for ab initio total-energy calculations using a plane-wave basis set. Phys. Rev. B 1996, 54 (16), 11169-11186.

3. Perdew, J. P.; Burke, K.; Ernzerhof, M., Generalized gradient approximation made simple. Phys. Rev. Lett. 1996, 77 (18), 3865-3868.

4. Klimes, J.; Bowler, D. R.; Michaelides, A., Van der Waals density functionals applied to solids. Phys. Rev. B 2011, 83 (19), 195131.

5. Kresse, G.; Joubert, D., From ultrasoft pseudopotentials to the projector augmented-wave method. Phys. Rev. B 1999, 59 (3), 1758-1775.

6. Monkhorst, H. J.; Pack, J. D., Special points for Brillouin-zone integrations. Phys. Rev. B 1976, 13 (12), 5188-5192.

7. Henkelman, G.; Uberuaga, B. P.; Jonsson, H., A climbing image nudged elastic band method for finding saddle points and minimum energy paths. J. Chem. Phys. 2000, 113 (22), 9901-9904.

8. Henkelman, G.; Jonsson, H., A dimer method for finding saddle points on high dimensional potential surfaces using only first derivatives. J. Chem. Phys. 1999, 111 (15), 7010-7022.

9. Wyckoff, R. W. G., Crystal Structures. 2nd edition ed.; Interscience Publishers: New York, 1963.

10. Mohd Adli, N.; Shan, W.; Hwang, S.; Samarakoon, W.; Karakalos, S.; Li, Y.; Cullen, D. A.; Su, D.; Feng, Z.; Wang, G.; Wu, G., Engineering Atomically Dispersed $\mathrm{FeN}_{4}$ Active Sites for $\mathrm{CO}_{2}$ Electroreduction. Angew. Chem. Int. Ed. 2021, 60 (2), $1022-$ 1032.

11. Gong, Y.-N.; Jiao, L.; Qian, Y.; Pan, C.-Y.; Zheng, L.; Cai, X.; Liu, B.; Yu, S.-H.; Jiang, H.-L., Regulating the Coordination Environment of MOF-Templated SingleAtom Nickel Electrocatalysts for Boosting $\mathrm{CO}_{2}$ Reduction. Angew. Chem. Int. Ed. 2020, 59 (7), 2705-2709.

12. Liu, W.; Zhang, L.; Liu, X.; Liu, X.; Yang, X.; Miao, S.; Wang, W.; Wang, A.; Zhang, T., Discriminating Catalytically Active $\mathrm{FeN}_{\mathrm{x}}$ Species of Atomically Dispersed $\mathrm{Fe}-\mathrm{N}-\mathrm{C}$ Catalyst for Selective Oxidation of the C - H Bond. J. Am. Chem. Soc. 2017, 139 (31), 10790-10798.

13. Yan, X.; Duan, P.; Zhang, F.; Li, H.; Zhang, H.; Zhao, M.; Zhang, X.; Xu, B.; Pennycook, S. J.; Guo, J., Stable single-atom platinum catalyst trapped in carbon onion graphitic shells for improved chemoselective hydrogenation of nitroarenes. Carbon 2019, 143, 378-384.

14. Nie, R.; Wang, J.; Wang, L.; Qin, Y.; Chen, P.; Hou, Z., Platinum supported on reduced graphene oxide as a catalyst for hydrogenation of nitroarenes. Carbon 2012, $50(2), 586-596$.

15. Takasaki, M.; Motoyama, Y.; Higashi, K.; Yoon, S.-H.; Mochida, I.; Nagashima, H., Chemoselective hydrogenation of nitroarenes with carbon nanofiber-supported 
platinum and palladium nanoparticles. Org. Lett. 2008, 10 (8), 1601-1604.

16. Motoyama, Y.; Lee, Y.; Tsuji, K.; Yoon, S.-H.; Mochida, I.; Nagashima, H., Platinum Nanoparticles Supported on Nitrogen-doped Carbon Nanofibers as Efficient Poisoning Catalysts for the Hydrogenation of Nitroarenes. ChemCatChem 2011, 3 (10), 1578-1581.

17. Wang, C.; Mao, S.; Wang, Z.; Chen, Y.; Yuan, W.; Ou, Y.; Zhang, H.; Gong, Y.; Wang, Y.; Mei, B.; Jiang, Z.; Wang, Y., Insight into single-atom-induced unconventional size dependence over $\mathrm{CeO} 2$-supported Pt catalysts. Chem 2020, 6 (3), 752-765.

18. Evangelisti, C.; Aronica, L. A.; Botavina, M.; Martra, G.; Battocchio, C.; Polzonetti, G., Chemoselective hydrogenation of halonitroaromatics over gammaFe2O3-supported platinum nanoparticles: The role of the support on their catalytic activity and selectivity. J. Mol. Catal. A-Chem. 2013, 366, 288-293.

19. Dhiman, M.; Polshettiwar, V., Ultrasmall nanoparticles and pseudo-single atoms of platinum supported on fibrous nanosilica $(\mathrm{KCC}-1 / \mathrm{Pt})$ : engineering selectivity of hydrogenation reactions. J. Mater. Chem. A 2016, 4 (32), 12416-12424.

20. Ma, Y.; Ren, Y.; Zhou, Y.; Liu, W.; Baaziz, W.; Ersen, O.; Pham-Huu, C.; Greiner, M.; Chu, W.; Wang, A.; Zhang, T.; Liu, Y., High-Density and Thermally Stable Palladium Single-Atom Catalysts for Chemoselective Hydrogenations. Angew. Chem. Int. Ed. 2020, 59 (48), 21613-21619.

21. Iihama, S.; Furukawa, S.; Komatsu, T., Efficient catalytic system for chemoselective hydrogenation of halonitrobenzene to haloaniline using PtZn intermetallic compound. ACS Catal. 2016, 6 (2), 742-746.

22. Yan, H.; Zhao, X.; Guo, N.; Lyu, Z.; Du, Y.; Xi, S.; Guo, R.; Chen, C.; Chen, Z.; Liu, W.; Yao, C.; Li, J.; Pennycook, S. J.; Chen, W.; Su, C.; Zhang, C.; Lu, J., Atomic engineering of high-density isolated Co atoms on graphene with proximal-atom controlled reaction selectivity. Nat. Commun. 2018, 9 (1), 3197.

23. Wang, L.; Zhu, C.; Xu, M.; Zhao, C.; Gu, J.; Cao, L.; Zhang, X.; Sun, Z.; Wei, S.; Zhou, W.; Li, W.-X.; Lu, J., Boosting Activity and Stability of Metal Single-Atom Catalysts via Regulation of Coordination Number and Local Composition. Zenodo 2021, doi: 10.5281/zenodo.5574298. 